\title{
Rapid attribution of the August 2016 flood-inducing extreme precipitation in south Louisiana to climate change
}

\author{
Karin van der Wiel ${ }^{1,2}$, Sarah B. Kapnick ${ }^{2}$, Geert Jan van Oldenborgh ${ }^{3}$, Kirien Whan $^{3}$, Sjoukje Philip ${ }^{3}$, \\ Gabriel A. Vecchi ${ }^{2}$, Roop K. Singh ${ }^{4}$, Julie Arrighi ${ }^{4}$, and Heidi Cullen ${ }^{5}$ \\ ${ }^{1}$ Program in Atmospheric and Oceanic Sciences, Department of Geosciences, Princeton University, Princeton, NJ, USA \\ ${ }^{2}$ Geophysical Fluid Dynamics Laboratory (GFDL), National Oceanic and Atmospheric Administration, Princeton, NJ, USA \\ ${ }^{3}$ Royal Netherlands Meteorological Institute (KNMI), De Bilt, the Netherlands \\ ${ }^{4}$ Red Cross Red Crescent Climate Centre, The Hague, the Netherlands \\ ${ }^{5}$ Climate Central, Princeton, NJ, USA
}

Correspondence to: Karin van der Wiel (wiel@knmi.nl) and Geert Jan van Oldenborgh (oldenborgh@knmi.nl)

Received: 31 August 2016 - Discussion started: 6 September 2016

Revised: 14 January 2017 - Accepted: 19 January 2017 - Published: 14 February 2017

\begin{abstract}
A stationary low pressure system and elevated levels of precipitable water provided a nearly continuous source of precipitation over Louisiana, United States (US), starting around 10 August 2016. Precipitation was heaviest in the region broadly encompassing the city of Baton Rouge, with a 3-day maximum found at a station in Livingston, LA (east of Baton Rouge), from 12 to 14 August 2016 (648.3 mm, 25.5 inches). The intense precipitation was followed by inland flash flooding and river flooding and in subsequent days produced additional backwater flooding. On 16 August, Louisiana officials reported that 30000 people had been rescued, nearly 10600 people had slept in shelters on the night of 14 August and at least 60600 homes had been impacted to varying degrees. As of 17 August, the floods were reported to have killed at least 13 people. As the disaster was unfolding, the Red Cross called the flooding the worst natural disaster in the US since Super Storm Sandy made landfall in New Jersey on 24 October 2012. Before the floodwaters had receded, the media began questioning whether this extreme event was caused by anthropogenic climate change. To provide the necessary analysis to understand the potential role of anthropogenic climate change, a rapid attribution analysis was launched in real time using the best readily available observational data and high-resolution global climate model simulations.

The objective of this study is to show the possibility of performing rapid attribution studies when both observational and model data and analysis methods are readily available
\end{abstract}

upon the start. It is the authors' aspiration that the results be used to guide further studies of the devastating precipitation and flooding event. Here, we present a first estimate of how anthropogenic climate change has affected the likelihood of a comparable extreme precipitation event in the central US Gulf Coast. While the flooding event of interest triggering this study occurred in south Louisiana, for the purposes of our analysis, we have defined an extreme precipitation event by taking the spatial maximum of annual 3-day inland maximum precipitation over the region of $29-31^{\circ} \mathrm{N}, 85-95^{\circ} \mathrm{W}$, which we refer to as the central US Gulf Coast. Using observational data, we find that the observed local return time of the 12-14 August precipitation event in 2016 is about 550 years $(95 \%$ confidence interval $(\mathrm{CI}): 450-1450)$. The probability for an event like this to happen anywhere in the region is presently 1 in 30 years (CI 11-110). We estimate that these probabilities and the intensity of extreme precipitation events of this return time have increased since 1900. A central US Gulf Coast extreme precipitation event has effectively become more likely in 2016 than it was in 1900 . The global climate models tell a similar story; in the most accurate analyses, the regional probability of 3-day extreme precipitation increases by more than a factor of 1.4 due to anthropogenic climate change. The magnitude of the shift in probabilities is greater in the $25 \mathrm{~km}$ (higher-resolution) climate model than in the $50 \mathrm{~km}$ model. The evidence for a relation to El Niño half a year earlier is equivocal, with some analyses showing a positive connection and others none. 


\section{Introduction}

In the second week of August, a storm system developed in the United States (US) Gulf Coast region and resulted in intense precipitation across south Louisiana in the region surrounding the city of Baton Rouge. The highest concentration of precipitation fell over the 3-day period of 12-14 August (Fig. 1a-d). On Saturday, 13 August the greatest total magnitude of precipitation and the broadest surface area of intense precipitation during the storm were experienced. The National Oceanic and Atmospheric Administration (NOAA) Climate Prediction Center (CPC) unified gauge-based gridded analysis of daily precipitation exhibits $25^{\circ} \times 25^{\circ} \mathrm{km}$ area boxes with precipitation maxima reaching up to $534.7 \mathrm{~mm}$ (21.1 inches) over the 3-day period. In station observations (a single point), a rain gauge in Livingston, LA (east of Baton Rouge), experienced an even higher 3-day precipitation total of $648.3 \mathrm{~mm}$ ( 25.5 inches). In places, the 3 -day precipitation totals in Louisiana exceeded 3 times those of the climatological August totals (historical average total precipitation that occurs over 31 days; Fig. 1e) and 3 times the average annual 3-day precipitation maximum (Fig. 1f).

The intense precipitation formed due to a low pressure system that originated near Florida/Alabama on 5 August. At that time, the National Hurricane Center stated that the low pressure system might transform into a tropical depression if it moved to the Gulf of Mexico (Schleifstein, 2016). Instead, the system remained over land and moved westward slowly. On 12 August, it became near stationary over Louisiana (Fig. 1a-c) allowing for the continuous development of thunderstorms in a localized area to the south and southeast of the low pressure center. The stationary storm system and anomalously moist atmospheric conditions (precipitable water exceeding $65 \mathrm{~mm}$ ) created optimal conditions for high precipitation efficiencies and intense precipitation rates. Though the system had a warm core and some similarities to a tropical depression, it never formed the closed surface wind circulation about a well-defined center that is needed to be classified as a tropical depression (National Weather Service, 2016; New Orleans area forecast discussions (PIL=AFDLIX), 2016).

Historic freshwater flooding in the region encompassing Baton Rouge, Louisiana, followed the extreme precipitation event. Provisional reports from 18 August 2016 showed stream gauges managed by the United States Geological Survey (USGS) registering above flood stage levels (levels at which overflow of natural banks starts to cause damage in the local area) at 30 sites and found that, out of 261 sites in all of Louisiana, 50 were overtopped by floodwaters (Burton and Demas, 2016). This was a complex event where rivers responded to local precipitation as well as upstream and downstream conditions (Fig. 2). For example, on the Comite River, a major drainage river for north Baton Rouge and its outlying districts, the provisional gauge height data exceeded the National Weather Service (NWS) flood stage from 12 to 16 August and exceeded the previous height record (set 19 May 1953). The Comite River hit its NWS flood stage level before the maximum precipitation fell in the central US Gulf Coast. Floodwaters were slow to recede due to flood stages downstream causing backwater flooding (upstream flooding caused by conditions downstream) in many neighborhoods (Burton and Demas, 2016). Further downstream on the Amite River, provisional data showed that water levels exceeded the NWS flood stage from 13 to 23 August and also exceeded the previous height record (set 25 April 1977). Its levels declined more slowly and did not fall below flood stage until late on 23 August, due to drainage from the Comite and other tributaries upstream that hit peak flood stage days earlier (Burton and Demas, 2016).

On 12 August, the NWS issued flash flood warnings for parishes in south Louisiana and activated the national Emergency Alert System which urged residents to move to higher ground. The Louisiana Coast Guard, National Guard and civilian volunteers mobilized to rescue over 30000 people from their flooded homes and cars (Broach, 2016). By August 14 , the federal government declared a major disaster, indicating that the severity of damage exceeded the local and state governments' combined capability to respond, initiating federal assistance for individuals and public infrastructure (Davies, 2016; FEMA, 2016; Stafford, 2000). The flooding impacted the state's agriculture industry with losses estimated in excess of USD 110 million (Allen and Burgess, 2016). Initial estimates also show that at least 60600 homes were damaged and 13 people were killed due to the floods (Strum, 2016). The American Red Cross, with FEMA and other federal and local agencies, provided shelter and emergency relief for 10600 people initially displaced by the disaster, and the American Red Cross estimates that its ongoing relief efforts will cost USD 30 million (American Red Cross, 2016a, b). To date, more than 110000 people have registered for federal disaster assistance (FEMA, 2016).

South Louisiana is a region where a number of phenomena can lead to flooding. For example, as a coastal region, it can experience saltwater flooding from a storm surge, when the low pressure and winds of a storm moving towards the coastline push coastal saltwater inland. This occurred in August 2005 when Hurricane Katrina impacted a broad swath of the Gulf Coast, including New Orleans, LA, with a large storm surge. Inland, precipitation can directly cause pluvial flooding by producing runoff in a region independent of a body of water (i.e., when more rain falls than can be soaked up by the ground) or fluvial flooding when water levels exceed the capacity of the river environment. For inland freshwater flooding, land surface conditions prior to an extreme precipitation event may increase the susceptibility of a region to both types of flooding, by saturating the soil (Tramblay et al., 2010; De Michele and Salvadori, 2002) or increasing river levels (Pinter et al., 2006). Inland flood conditions can also be induced by water flowing through the river system after a storm due to capacity limitations, as evident along the 


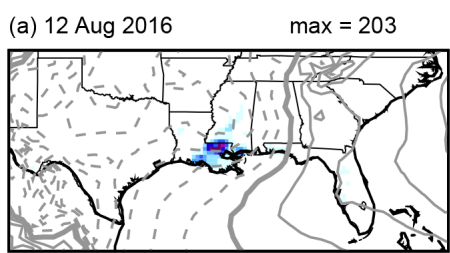

(d) 12-14 Aug 2016

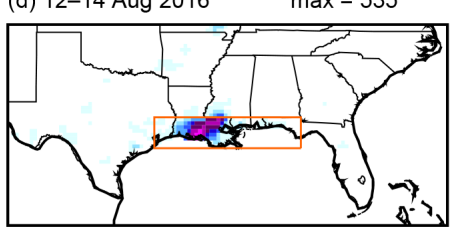

(b) 13 Aug 2016

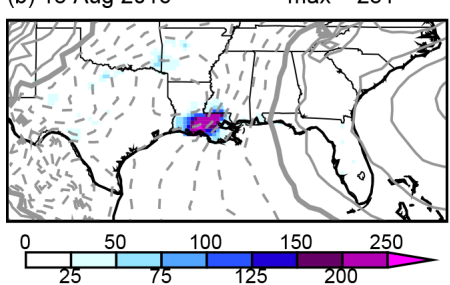

(e) Climatological August total

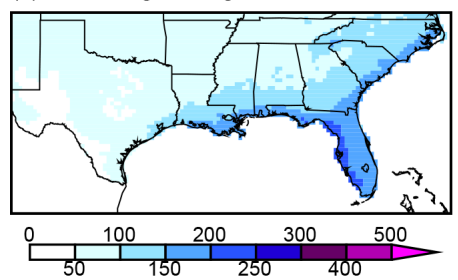

(c) 14 Aug $2016 \quad \max =183$

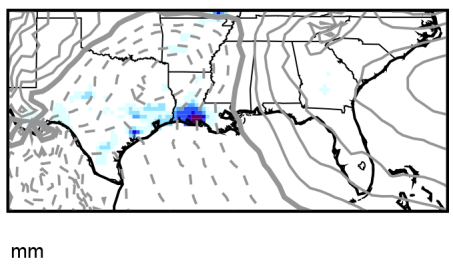

(f) Average annual 3-day extreme

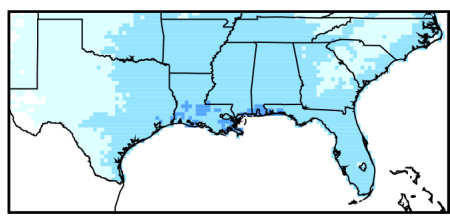

$\mathrm{mm}$

Figure 1. (a, b, c) Daily precipitation (shaded colors) and sea level pressure (grey contours, interval $1 \mathrm{hPa}, 1015 \mathrm{hPa}$ contour thickened, lower contours dashed) for 12, 13 and 14 August 2016. (d) The 3-day precipitation sum for 12-14 August 2016. (e) August climatological total precipitation (1948-2015). (f) Average annual maximum 3-day precipitation event (1948-2015). Orange box in (d) shows the geographic region used for the analysis $\left(29-31^{\circ} \mathrm{N}, 85-95^{\circ} \mathrm{W}\right)$. Data are from CPC unified gauge-based analysis of daily precipitation over the contiguous US (2016 data are from the real-time archive) and ECMWF operational analysis.

(a) Comite river near comite

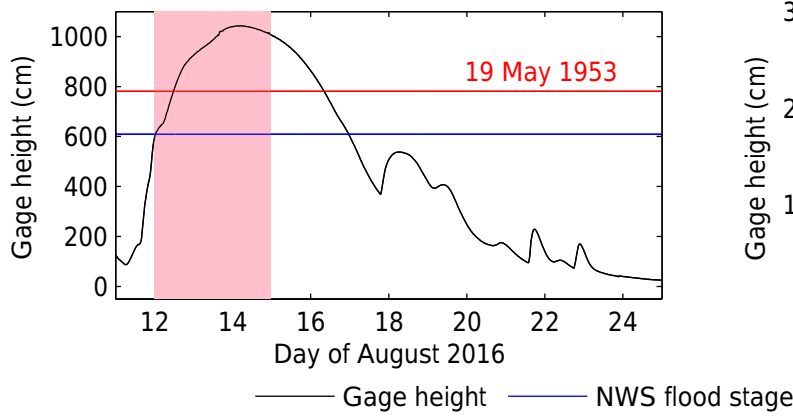

(b) Amite river near french settlement

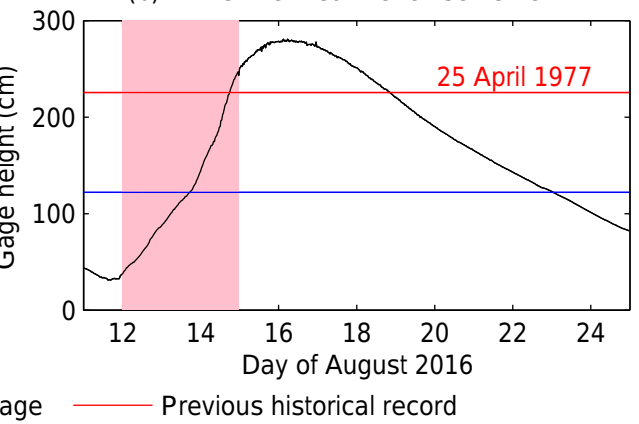

Figure 2. Hydrographs of gauge levels, NWS flood stage value and previous historical record for USGS station (a) 07378000 on the Comite River and (b) 07380200 on the Amite River. Shaded pink areas indicate the 3-day period of maximum precipitation (12-14 August 2016). Observed stream gauge information was downloaded 25 August 2016 from the USGS: http://waterdata.usgs.gov/la/nwis/uv?; provisional USGS data are subject to adjustment: http://help.waterdata.usgs.gov/policies/provisional-data-statement.

Amite River in August 2016 (Fig. 2b) due to upstream flood conditions making their way downstream. Flooding can be influenced by remote meteorological conditions as river networks connect regions over vast areas. Louisiana had most recently experienced widespread inland flooding in MarchApril 2016. Although inland freshwater flooding occurs due to a combination of the level of extreme precipitation and its interaction with the land surface and river system, including human modifications to those systems and responses to events, we have chosen to focus our rapid attribution study on one portion of the problem: understanding the present and potentially climate-change-influenced probability of extreme precipitation events like the one which occurred in August 2016.
Synoptic forcing for precipitation extremes in the Gulf Coast region includes both midlatitude weather (cold-core systems fueled by baroclinic instability) and tropical weather (warm-core systems with barotropic instability). Extreme precipitation has historically been classified into three types of events: frontal systems, tropical systems and air mass systems. Each of these categories can be further broken down: e.g., tropical systems ranging from easterly waves to hurricanes, frontal systems including interactions between the polar jet and moist air masses from the gulf, squall lines or mesoscale convective systems and air mass systems that may include heavy rainfall from upper air disturbances, or convective storms that form because of daytime heating (Keim and Faiers, 1996). The variety of weather systems that can give rise to precipitation extremes in the region complicates 
the statistical analysis of the extremes and requires climate models to capture the entire distribution in a realistic manner. Also, the response to radiative forcing may be nonlinear: thermodynamic and/or dynamic changes may be different for different weather systems (O'Gorman, 2015).

In this article, we analyze the historical context and changes in statistics of extreme precipitation like the one experienced during August 2016 in south Louisiana by defining an extreme event by its local or regional maximum 3-day precipitation. We have focused our analysis on stations or land surface grid cells in the region of $29-31^{\circ} \mathrm{N}, 85-95^{\circ} \mathrm{W}$ (illustrated by the orange box in Fig. 1d), which we hereafter refer to as the central US Gulf Coast. Here, we report the results of our rapid attribution study conducted by several organizations within 2 weeks of the event. The need for a rapid attribution study arises from the current intense public discussion that results from the significant societal impacts of this particular event and a continuous general interest in climate change. Media coverage following the event has linked into the growing body of scientific evidence that precipitation extremes are expected to increase due to the greater moisture content of a warmer atmosphere following ClausiusClapeyron scaling (O'Gorman, 2015; Lenderink and Attema, 2015; Scherrer et al., 2016): e.g., "Disasters like Louisiana floods will worsen as planet warms, scientists warn" (Milman, 2016), "Flooding in the South looks a lot like climate change" (Bromwich, 2016). However, specific scientific statements for the event as observed in south Louisiana cannot be made based on general assessments of the connection of global warming and extreme rainfall. While attribution studies at a more traditional scientific pace (several months up to a year later) are important and add to scientific understanding of changing extremes, reporting results recently after an extreme event may enhance the societal understanding of climate change and extreme weather and provide often-requested information for management decisions following the event.

The methodologies employed in this study are used regularly in the literature and were previously applied to the rapid attribution of the French and German 2016 flooding event (van Oldenborgh et al., 2016) and of Storm Desmond over the UK in 2015 (van Oldenborgh et al., 2015). The presented analysis builds upon these methodologies for event attribution and also explores the role of climate variability. We have made a few carefully considered, crucial assumptions to facilitate the analysis. For example, these include assumptions on the statistical distribution of 3-day precipitation in the area, the suitability of observational data and global climate models and the connection between extreme precipitation and global mean surface temperature. Please see Sect. 7 for a detailed discussion of all crucial assumptions and their potential impact on the results.

The present study is limited to investigation of changing precipitation statistics. Rapid attribution of flood risk was not feasible within the time frame and given our access to suit- able data and models. Note that a "climate attribution" is fundamentally different from a deterministic synoptic attribution, a detailed analysis of the chain of events that led to the extreme rainfall is not provided. The trends and internal climate variability of extreme precipitation are investigated in station observations, gridded gauge-based precipitation analysis and high-resolution global climate model simulations. Since this paper aims to provide a first attribution assessment of the 2016 south Louisiana extreme event, we have provided a detailed data and methods section (Sect. 2) in which our data sets, statistical calculations for return periods and trends and data set validation methodologies are described. The rest of the paper is organized as follows: Sect. 3 provides observational analysis. In Sect. 4, we evaluate the suitability of the global climate models. Model analysis is provided in Sect. 5. Section 6 synthesizes our conclusions. In Sect. 7, we provide a detailed discussion of crucial assumptions and their potential impact on the results, further avenues of research and implications of this work.

\section{Data and methods}

\subsection{Observational data}

We utilize both point station observations and gridded analysis in this paper. The point station data are from the Global Historical Climatology Network daily product (GHCN-D) version 3.22 (Menne et al., 2012, 2016). The data set provides daily observations for stations worldwide. Data are quality controlled before becoming available in near-real time. Inside the defined central US Gulf Coast (Fig. 1d), 324 stations with a minimum of 10 years of data are available for the period 1891 to present (August 2016). However, not all stations provide data for the entire period, and spatial proximity between stations means that not all data points provide independent information (see Sect. 7.1). Therefore, for some analyses, a smaller selection of the available stations is taken into account. Selection criteria are described in the relevant sections.

The gridded analysis used here is the product of the NOAA CPC unified gauge-based analysis of daily precipitation over the contiguous US (Higgins et al., 2000). The data set interpolates point station data on a $0.25^{\circ} \times 0.25^{\circ}$ uniform latitude-longitude grid, based on the optimal interpolation scheme of Gandin and Hardin (1965). The CPC data set covers the period 1 January 1948 to present (August 2016); data from 2007 onwards have been made available in real time. Because this is a gridded product, daily precipitation sums represent an areal average $\left(0.25^{\circ} \times 0.25^{\circ}\right)$ rather than a point measurement. Therefore, precipitation extremes are expected to be of smaller magnitude in the gridded product (Chen and Knutson, 2008), as was noted for the south Louisiana event above (3-day total maxima of $534.7 \mathrm{~mm}$ in the CPC gridded versus $648.3 \mathrm{~mm}$ in the point station data). The gridded anal- 
ysis and the individual station data are not independent, as the precipitation station data are the underlying source for the gridded analysis; consequently, changes in gauge station density in space and time (as discussed above for GHCN-D) also impact the gridded analysis. We note that for comparisons with climate models - in which precipitation represents area averages and not point values - the area-averaged precipitation values from the gridded analysis are likely more meaningful for comparison with models than point station data (Chen and Knutson, 2008; Eggert et al., 2015).

We use the National Aeronautics and Space Administration (NASA) Goddard Institute for Space Science (GISS) surface temperature analysis (GISTEMP Team, 2016; Hansen et al., 2010) for estimates of the development of global mean surface temperature over time. This gridded data set is based on the GHCN point station data over land, NOAA Extended Reconstructed Sea Surface Temperature (ERSST; Huang et al., 2015) version 4 over oceans and Scientific Committee on Antarctic Research (SCAR) point station data for Antarctica.

\subsection{Model and experiment descriptions}

Many of the meteorological phenomena that cause extreme precipitation at the central US Gulf Coast are small in scale; therefore, only high-resolution models can simulate them realistically. We verified that the Royal Netherlands Meteorological Institute (KNMI) EC-Earth 2.3 T159 experiments ( $\sim 150 \mathrm{~km}$; Hazeleger et al., 2012) and the United Kingdom (UK) Met Office HadGEM3-A N216 ( 60 km; Christidis et al., 2013) models do not realistically represent precipitation extremes in the region.

We therefore use two higher-resolution global climate models in our analysis from the NOAA Geophysical Fluid Dynamics Laboratory (GFDL). Both models were developed from the GFDL Coupled Model version 2.1 (CM2.1; Delworth et al., 2006) using a cubed-sphere finite volume dynamical core (Putman and Lin, 2007) with 32 vertical levels. Atmospheric physics are taken from the GFDL Coupled Model version 2.5 (CM2.5; Delworth et al., 2006, 2012). The two models share the same ocean and sea ice components with a $1^{\circ}$ horizontal resolution but differ in their atmosphere and land horizontal resolution. In the forecast-oriented low ocean resolution model (FLOR, Vecchi et al., 2014), there are 180 points along each cubed-sphere finite volume dynamical core face (FV3-C180), which relates to a resolution of $0.5^{\circ}$ per cell along the Equator. This has been interpolated to a $0.5^{\circ} \times 0.5^{\circ}$ uniform latitude-longitude grid. In the high-resolution version of the model (HiFLOR; Murakami et al., 2016), there are 384 points along each face (FV3-C384) on the cubed-sphere finite volume dynamic core, which relates to a resolution of $0.23^{\circ}$ per cell along the Equator. This has been interpolated to a $0.25^{\circ} \times 0.25^{\circ}$ uniform latitudelongitude grid. For FLOR, we use a flux-adjusted version of the model (FLOR-FA), in which atmosphere-to-ocean fluxes of momentum, enthalpy and freshwater are adjusted to bring the simulated fields closer to their observed climatological state. This procedure reduces model biases of, for example, sea surface temperatures (SSTs), tropical cyclones (Vecchi et al., 2014) and precipitation patterns. We assume the modeled response to changes in radiative forcing is not impacted by the flux adjustment (see Sect. 7.1). The adjustment method is described in detail in Vecchi et al. (2014). Descriptions on how to access the data used in this study are provided in the data availability section.

Table 1 describes six different global coupled model experiments that have been performed using FLOR-FA and HiFLOR, which - for each model - differ in the type of radiative forcing that is prescribed, thus allowing us to assess the impact of radiative forcing on the statistics of weather extremes in these models. With FLOR-FA, there are two sets of experiments. First, we made use of a multicentennial integration in which values of radiative forcing agents (solar forcing, anthropogenic and natural aerosols, well-mixed greenhouse gases, ozone, etc.) are prescribed to remain at levels representative of a particular time - the mid-19th century in this case (Jia et al., 2016); radiative forcing agents are prescribed at the 1860 values following the protocol of the Fifth Coupled Model Intercomparison Project (CMIP5, Taylor et al., 2012). These types of experiments with global climate models are often referred to as "control" experiments ("pre-industrial control" in this particular case) but here we label this class of experiments as "static radiative forcing" experiments, since with HiFLOR we fix radiative forcing at a number of levels. In the static radiative forcing experiments, the years of the integration bear no relation to the real-world calendar. The second set of experiments with FLOR-FA is a suite of five realizations (or "ensemble members") in which the radiative forcing is prescribed to follow estimates of past and future radiative forcing changes over the period 1861-2100 (Jia et al., 2016); the forcing agents for the period 1861-2005 are prescribed to follow the CMIP5 historical experiment protocol, and for the period 2005-2100 they follow the CMIP5 Representative Concentration Pathway 4.5 (RCP4.5), which represents the medium-range greenhouse gas emissions scenario (Van Vuuren et al., 2011). The five realizations of the 1861-2100 experiments differ only in their initial conditions on 1 January 1861, which are taken from five different years from the long FLOR-FA pre-industrial static forcing experiment. In these experiments, the calendar of the experiments is connected to the history of radiative forcing - but the internal climate variations (e.g., El Niño events) and weather fluctuations (e.g., individual storms) are not constrained to follow their observed sequence. The static climate experiment has a slow drift because the slow climate components, notably the deep ocean, were not in equilibrium at the beginning of the run; this is most noticeable in the first 1000 years of the integration.

With HiFLOR, there are four experiments to explore the climate sensitivity of the statistics of weather events through 
Table 1. Global coupled model experiments performed with the FLOR-FA and HiFLOR models.

\begin{tabular}{llrrr}
\hline Model & Type of forcing & $\begin{array}{r}\text { Representative } \\
\text { year of forcings }\end{array}$ & $\begin{array}{c}\text { No. of } \\
\text { ensembles }\end{array}$ & $\begin{array}{r}\text { No. of modeled } \\
\text { years in total }\end{array}$ \\
\hline FLOR-FA & Static radiative forcing & 1860 & 1 & 3550 \\
FLOR-FA & $\begin{array}{l}\text { Time-varying radiative } \\
\text { forcing }\end{array}$ & $1861-2100$ & 5 & 1200 (five realizations \\
of 240 years) \\
HiFLOR & Static radiative forcing & 1860 & 1 & 200 \\
HiFLOR & Static radiative forcing & 1940 & 1 & 75 \\
HiFLOR & Static radiative forcing & 1990 & 1 & 300 \\
HiFLOR & Static radiative forcing & 2015 & 1 & 70 \\
\hline
\end{tabular}

static radiative forcing experiments at levels representative of particular times: pre-industrial conditions (fixed at 1860 values), mid-20th century (fixed at 1940 values), late 20th century (fixed at 1990 values) and early 21 st century (fixed at 2015 values). The value of radiative forcing agents in these experiments is prescribed from either the CMIP5 historical forcing protocol (for the 1860, 1940 and 1990 static forcing experiments) or from the CMIP5 RCP4.5 protocol (for the 2015 static forcing experiment); the coupled atmosphereland-ocean-sea ice state of the model is left to evolve freely. These simulations have been integrated for different lengths of time (Table 1, last column), over which they generate their own climate under the fixed forcing; longer integrations allow us to better estimate the statistics of climate extremes, but these were the lengths of integrations available as of 15 August 2016.

There are many fewer model years available with HiFLOR than FLOR-FA because the HiFLOR model was developed more recently, and because the HiFLOR model is substantially more computationally intensive ( $\sim 6$ times the computer resources required for 1 year of integration) than FLOR-FA. The four HiFLOR static forcing experiments are initialized from the same ocean, atmosphere, land and sea ice initial conditions, which are representative of the observed state in the late 20th century, and the four experiments are not in radiative balance through the length of integration (the 1860 experiment has a negative top-of-atmosphere balance, while the 1940, 1990 and 2015 experiments have positive balances). Therefore, these static climate experiments each exhibit an initial rapid ( $\sim 20$ years) adjustment away from the late 20th century observed initial conditions and a slower climate drift reflecting the top-of-atmosphere imbalance over the length of the integration. We exclude the first 20 years of each integration from our analysis and assume that the impact of the slow climate drift in each model experiment on the statistics of precipitation extremes is small (see justification in Sect. 7.1).

In addition to the coupled model experiments discussed above, in which the history of SSTs in the models emerges from the dynamics of the models and the changes in radiative forcing, for HiFLOR a set of variable forcing experi- ments were run over 1971-2015 in which the model is constrained by both historical radiative forcing and the observed history of monthly SST (Table 2). These experiments can be used to connect the statistics of rainfall extremes to the detailed history of SSTs that occurred over the past 45 years, part of which was a response to radiative forcing changes and part of which emerged from internal climate variations. Furthermore, by construction, these experiments have a substantially smaller SST bias than the free-running versions of HiFLOR, as the statistics of weather extremes and their connection to larger-scale climate can be substantially affected by SST biases (e.g., Vecchi et al., 2014; Krishnamurthy et al., 2015; Pascale et al., 2016). These experiments are described in more detail in Murakami et al. (2015) and Van der Wiel et al. (2016). The model SST was restored to the interannually varying observed field $\left(\mathrm{SST}_{T}\right)$ Met Office Hadley Centre SST product (HadISST1.1; Rayner et al., 2003) by adding an extra term to the modeled SST tendency:

$\frac{\mathrm{dSST}}{\mathrm{d} t}=O+\frac{1}{\tau}\left(\mathrm{SST}_{T}-\mathrm{SST}\right)$,

with $\tau$ the restoring timescale (three ensemble members were produced with $\tau=5$ days, three with $\tau=10$ days).

\subsection{Defining an extreme event and its statistics}

To classify the August 2016 south Louisiana precipitation event, we must choose a definition for the event to guide our statistical analysis of observations and model experiments. We have chosen to classify extremes using multi-day averaged precipitation rather than single-day precipitation, to reflect the aspects of the event that resulted in the flooding of several rivers in the area. The following steps are taken to calculate our event statistics in the model and observations.

1. We create 3-day precipitation averages in station points/grid cells over land found in the central US Gulf Coast at $29-31^{\circ} \mathrm{N}, 85-95^{\circ} \mathrm{W}$, which has a relatively homogenous average precipitation extreme magnitude (Fig. 1f). This provides us with, for each point in space, 365 values per year (366 in leap years) for each station point/grid cell, except the last and first years in 
Table 2. Restored SST experiments performed with the HiFLOR model.

\begin{tabular}{llrcc}
\hline Model & Type of forcing & $\begin{array}{r}\text { Representative } \\
\text { year forcings }\end{array}$ & $\begin{array}{c}\text { No. of } \\
\text { ensembles }\end{array}$ & $\begin{array}{l}\text { No. of modeled } \\
\text { years in total }\end{array}$ \\
\hline HiFLOR & $\begin{array}{l}\text { Time-varying radiative forcing (CMIP5 Historical and RCP4.5); } \\
\text { SSTs restored to observed monthly observations }\end{array}$ & $1971-2015$ & 6 & $\begin{array}{l}270 \text { (six realizations } \\
\text { of 45 years) }\end{array}$ \\
\hline
\end{tabular}

the record when there are 364 values per year $(365$ in leap years), since the first 1 January and last 31 December are dropped.

2. We then, at each point in space, calculate the annual maximum for each year and define it as the local extremum for the year to create a set of extreme values for further analysis.

3. For some analyses, we then take the maximum over the central US Gulf Coast region. We have carefully documented in the main text when this is the case.

4. In the static forcing model experiments, we disregard the first 20 years of data to allow for some initial spinup of the model in each new static forcing state.

In order to estimate the observed return periods using the 3-day annual events found above, we fit the resulting data to a generalized extreme value (GEV) distribution (Coles, 2001) in a similar manner as previously done for rapid attribution of the 2015 storm Desmond over the UK (van Oldenborgh et al., 2015) and for the rapid attribution of the 2016 flooding in France and Germany (van Oldenborgh et al., 2016). We first analyze the GEV distribution of observations and model simulations to determine if they represent the statistics of extreme precipitation events sufficiently to employ them in further work. To account for possible changes due to anthropogenic climate change over time, we scale the distribution with the 4-year smoothed global mean temperature (GISTEMP for observational analysis, modeled global mean $2 \mathrm{~m}$ air temperature for model analysis), a measure of the uniform global climate response to forcing. The GEV function is represented by

$$
\begin{aligned}
F(x) & =\exp \left[-\left(1+\xi \frac{x-\mu}{\sigma}\right)^{1 / \xi}\right] \\
\mu & =\mu_{0} \exp \left(\frac{\alpha T^{\prime}}{\mu_{0}}\right) \\
\sigma & =\sigma_{0} \exp \left(\frac{\alpha T^{\prime}}{\mu_{0}}\right)
\end{aligned}
$$

where $\mu$ is the location parameter, $\sigma$ is the scale parameter and $\xi$ represents the shape parameter of the curve. The ratio of $\sigma / \mu$ reduces to the constant $\sigma_{0} / \mu_{0}$. The fit is estimated using a maximum likelihood method where $\sigma, \mu_{0}, \sigma_{0}$ and $\xi$ are varied. There is a penalty term on $\xi$ : a Gaussian with a width of 0.2 is added to the likelihood function such that values larger than $\sim 0.4$ are penalized as unphysical. This is mainly used to restrain fits to the 1000-member nonparametric bootstrap that is used to estimate uncertainty. All years are assumed to be independent for this analysis; however, correlations between proximate stations or ensemble members (when available) are taken into account with a moving block bootstrap technique (Efron and Tibshirani, 1998). The average number of dependent stations will be noted in the analysis.

The GEV is first estimated for observational data to provide a baseline for validation. We then evaluate the individual models by assessing the extent to which the GEV fit parameters $(\mu, \sigma$ and $\xi$ ) are similar to those fitted to the longest available observational analysis (GHCN-D). As in van Oldenborgh et al. (2016), multiplicative bias correction is employed for the model data, which tends to improve the similarity of the GEV fit from the model and the observations.

After a conditional GEV fit has been computed, with global mean surface temperature as the covariate, Eq. (2) can be inverted to find the probability of the south Louisiana event in any year. We thus estimate the probability for the south Louisiana event in $2016, p_{1}$, and its probability in some earlier year, $p_{0}$ taken as 1860,1900 or the first year with available data (if that is later). This year is taken as representative for a climate that has not yet been strongly influenced much by anthropogenic climate change. The probabilities for an event with a magnitude at least as great as that observed in south Louisiana in each year, $i$, can be expressed as return times, $\tau_{i}$, by

$\tau_{i}=1 / p_{i}$

The ratio of probabilities or return periods from different years is known as the risk ratio (RR) where

$\mathrm{RR}=p_{1} / p_{0}=\tau_{0} / \tau_{1}$.

The risk ratio is a measure of how the likelihood of an event has changed in the target year (e.g., 2016) versus a reference year (e.g., 1900). An RR value of 1 would mean that the likelihood has not changed in the baseline year versus the target year. This ratio is therefore an indicator of changes in likelihood, but alone it cannot attribute this difference to a given mechanism.

There are multiple methods available to evaluate the impact of radiatively forced climate change on the change in likelihood of events. For FLOR-FA, we repeat the analy- 
sis for the observations using data from the transient experiments. The natural variability from an ensemble member of the model is uncorrelated with that of other ensemble members, or the real world, so common changes in the ensemble members are therefore due to the prescribed external forcings. Multidecadal changes over the past century are dominated by anthropogenic forcings. For the highestresolution global climate model, HiFLOR, we fit a concatenated time series of maximum precipitation and the corresponding global mean temperatures from the four static forcing experiments to Eq. (2). Furthermore, in HiFLOR, we fit the trends in extremes in the variable forcing six-member ensemble covering 1971-2015. These simulations feature restored SSTs which reduce oceanic temperature biases compared to a fully free-running ocean component and include the same oceanic variability as the real world (e.g., El Niño events, North Atlantic decadal variability).

We use the same procedure to investigate the effect of the El Niño-Southern Oscillation (ENSO) on extreme precipitation on the central US Gulf Coast, replacing the smoothed global mean temperature by an index of the strength of $\mathrm{El}$ Niño as a covariate in Eq. (2). As the 2016 flooding occurred half a year after a strong El Niño event, we take as an index a detrended version of the Niño 3.4 index with a lag of 6 months. The detrending is done by subtracting the average SST over $30^{\circ} \mathrm{S}-30^{\circ} \mathrm{N}$.

\section{Observational analysis}

We here describe the character of the statistical distribution of observed precipitation extremes and their trends in the GHCN-D point station data and the CPC gridded analysis by fitting to a time-dependent GEV distribution (described in Sect. 2.3). Due to the many different meteorological phenomena that can lead to precipitation extremes in the central US Gulf Coast, we assess the extent to which the GEV gives a satisfactory description of the underlying data. We frame the results around measures of the probability per year of an event at least as intense as the 2016 south Louisiana event (expressed as a return time) and the change of return time from the beginning of the data set to present (risk ratio). These return times can be assessed at a local scale (the expected wait time for an event at a particular place) or at a regional scale (the expected return time for an event somewhere in the central US Gulf Coast). Because the spatial scale of the most extreme precipitation events is substantially smaller than the whole region, the local return times are longer than the regional return times. This observational analysis on its own is only able to detect whether a trend is present but cannot ascribe cause(s) to these trends. Note that from here onwards we will principally report 3-day average precipitation values rather than 3-day precipitation sums, unless stated otherwise.

\subsection{Point station data}

We first analyze point station data, as extremes are affected by interpolation and station density, using the GHCN-D v3.22 data set. This first analysis does not take the spatial maximum (Step 3 in Sect. 2.3) but analyzes all stations in the region with at least 10 years of data. This gives 324 stations with 12536 station years with data (Fig. 3a), though it is crucial to note that they are not all statistically independent. The highest observed value at these gauges in 2016 is $216.1 \mathrm{~mm} \mathrm{day}^{-1}$ at Livingston, LA, on 12-14 August (648.3 mm, 3-day sum).

Fitting these data to a time-dependent GEV distribution as described in Sect. 2.3 gives a reasonable description of the data (Fig. 3c, e), although the fit is shaped mainly by the lower-intensity events, and the highest-intensity events align closer to the lower bound. It should be noted that for each point station in the data set, on average another 18 are correlated with $r>1 / e$, so the number of degrees of freedom is much less than the number of points. Overall, it is surprising that all different meteorological situations that can give rise to extreme precipitation (as laid out in Sect. 1) can be described with a single GEV function.

The local return time of a $216.1 \mathrm{~mm} \mathrm{day}^{-1}$ event at a station in 2016 is about 550 years $(95 \%$ confidence interval, CI, 450-1450 years). The probability of a 3-day precipitation event at a station with $216.1 \mathrm{~mm} \mathrm{day}^{-1}$ or more has increased by a factor of 4.5 (CI 3.0-5.5) since 1900 in this analysis. This corresponds to an increase in intensity for a given return time of $22 \%$ (CI 16-22\%).

This fit of all data available may be influenced by the spatially and temporally varying numbers and locations of stations. We therefore evaluate the impact of these changes in sampling on the results by limiting the analysis to stations with at least 80 years of data and at least $0.5^{\circ}$ of spatial separation between stations. This leaves 19 stations with 1849 station years (Fig. 3b), which results in 2.3 stations per degree of freedom on average. This analysis gives similar results: a return time of about 500 years (CI 360-1400) and an increase in probability of a factor of 2.8 (CI 1.7-3.8), corresponding to an increase in intensity of $17 \%$ (CI 10-21\%); Fig. 3d, f. The increase in probability is less than in the full station sample, although compatible within the $2 \sigma$ uncertainties.

Our final analysis of point station data focuses on the most intense events only by considering the spatial maximum of 3-day averaged precipitation anywhere in the central US Gulf Coast (Step 3 in Sect. 2.3). This answers the question how likely an event, like that in south Louisiana in 2016 (or worse), was anywhere in the region, rather than at a specific place. In the point station data, the spatial maximum is only homogeneous when the number of stations does not vary by much. We therefore again consider only those stations with at least 80 years of data but do not require a minimum distance this time. The number of stations increases up to around 40 


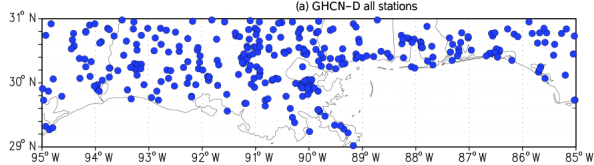

(c) GHCN-D all stations: location parameter
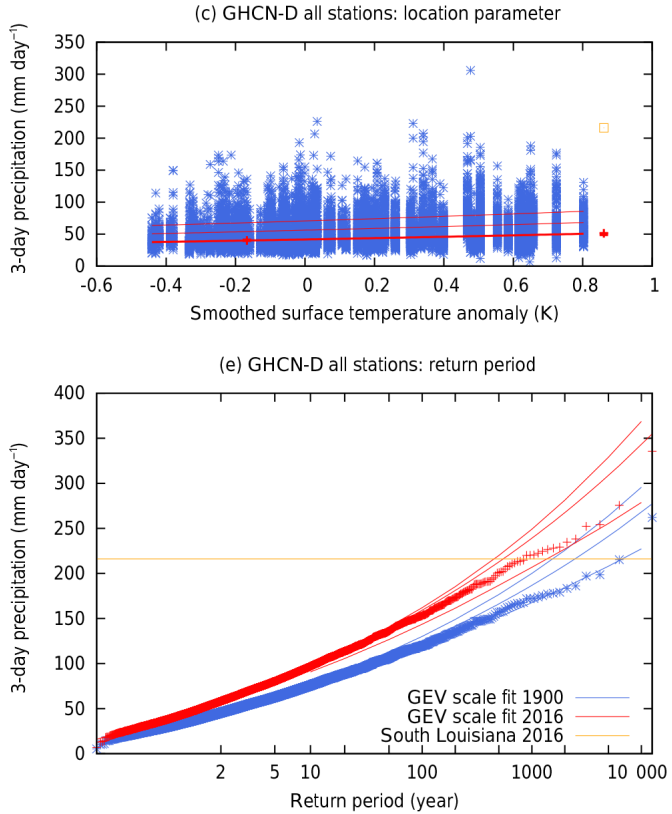

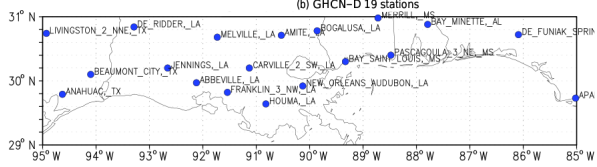

(d) GHCN-D 19 stations: location parameter
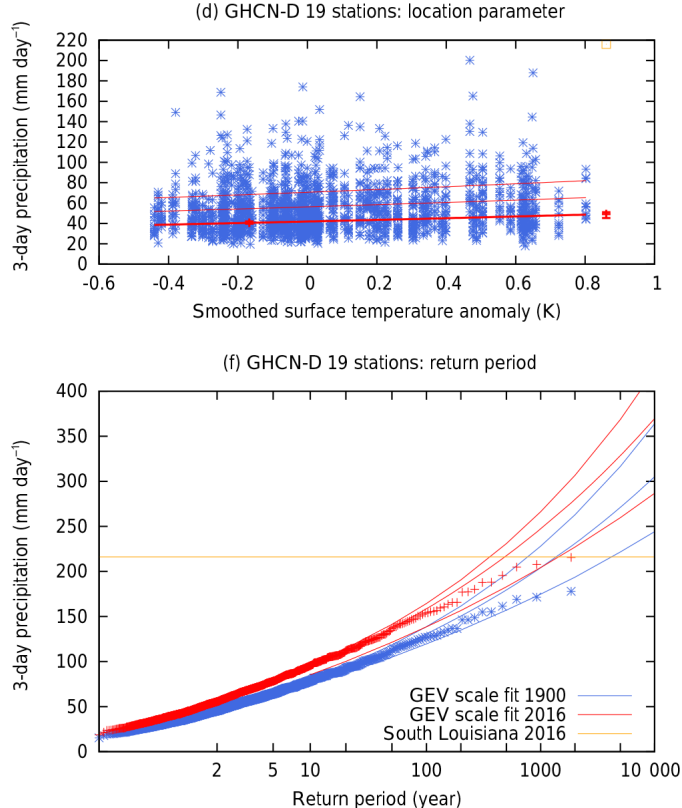

Figure 3. Fit of the annual maximum 3-day average GHCN-D station precipitation on the central US Gulf Coast to a GEV that scales with smoothed global mean surface temperature. (a) Location of all GHCN-D stations with minimum 10 years of data, (c) observations (blue marks), location parameter $\mu$ (thick red line versus global mean temperature anomalies, relative to 1980-2010), $\mu+\sigma$ and $\mu+2 \sigma$ (thin red lines); the two vertical red lines show $\mu$ and its $95 \%$ CI for the two climates in (e). (e) Gumbel plot of the GEV fit in 2016 (red line, with $95 \%$ uncertainty estimates) and 1900 (blue line); marks show data points drawn twice: scaled up with the trend to 2016 and scaled down to 1900. The yellow square (line) denotes the intensity of the observed event at Livingston, LA. Panels (b, d, f) are the same as (a, c, e) but for 19 GHCN-D stations with a minimum 80 years of data and minimum spatial separation of $0.5^{\circ}$.

in 1950-1980 and decreases again to the present. On average, 1.3 stations are correlated at $r>1 / e$ with each of these stations. We consider the period 1930-2016. The decrease in number of stations at the end implies that a trend in extremes will be negatively biased. The number of events is lower than before (1 per year instead of 19/324 events per year), so the uncertainties are larger.

A fit of a time-dependent GEV to the annual and spatial maximum of 3-day averaged precipitation describes the data well (Fig. 4). The return time for an event like that in south Louisiana in 2016 anywhere in the central US Gulf Coast is currently around 30 years (between 11 and 110 years with $95 \% \mathrm{CI}$ ). This is a factor of 6.3 (CI 2.1-50) more than it was in the climate of 1930 , corresponding to an increase of intensity of about $25 \%$ (CI 12-35\%).

Analyses of station data analogous to the ones above but for the season July-August-September (JAS) show somewhat smaller trends but with larger error margins. The estimated ranges of the JAS analyses and the all-year analyses overlap.

\subsection{Gridded analysis}

To compare with the model data, we also analyzed the CPC $0.25^{\circ} \times 0.25^{\circ}$ gridded precipitation analysis of 1948-2016. Because the spatial extent of 3-day averaged precipitation extremes is larger than the grid boxes, we first averaged these to a $0.5^{\circ} \times 0.5^{\circ}$ latitude-longitude grid. The highest value in 2016 is then $158.77 \mathrm{~mm} \mathrm{day}^{-1}$, which is the highest in the record. This is lower than at a single grid point due to the spatial averaging. A GEV fit of all $0.5^{\circ}$ grid points (not shown) gives a return time of 550 years with an uncertainty from 300 to 2000 years, compatible with the station analysis but with larger uncertainties. The probability has increased by a factor of 3.5 (CI 2.0-11) since 1948, corresponding to an increase in intensity of $15 \%$ (CI 9-24\%).

Taking the spatial maximum of the original $0.25^{\circ} \times 0.25^{\circ}$ grid we find that the highest observed value in 2016 is $178.2 \mathrm{~mm} \mathrm{day}^{-1}$ on $12-14$ August (534.7 $\mathrm{mm}$ in 3 days). The record is too short to draw robust conclusions from a fit of a GEV depending on global mean temperature except that the precipitation maxima also increase in this data set (Fig. 5). In 

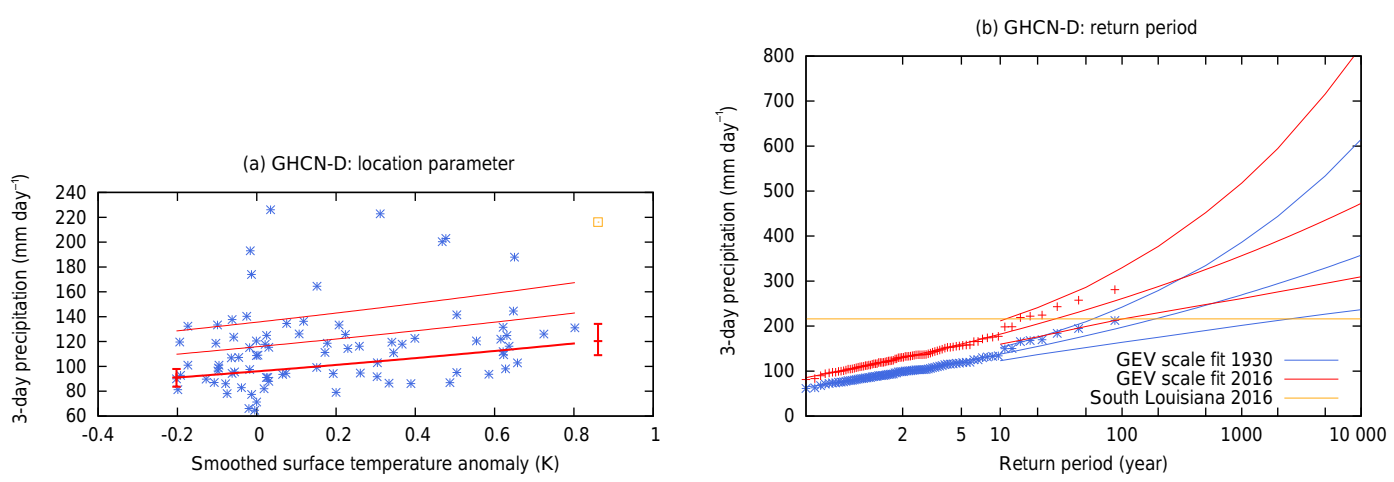

Figure 4. Fit of the spatial and annual maximum 3-day average GHCN-D station precipitation on the central US Gulf Coast to a GEV that scales with smoothed global mean surface temperature. (a) Observations (blue marks), location parameter $\mu$ (thick red line), $\mu+\sigma$ and $\mu+2 \sigma$ (thin red lines versus global mean temperature anomalies); the two vertical red lines show $\mu$ and its $95 \%$ confidence interval for the two climates in (b). (b) Gumbel plot of the GEV fit in 2016 (red line, with $95 \%$ uncertainty estimates) and 1930 (blue line); marks show data points drawn twice: scaled up with the trend to 2016 and scaled down to 1900 . The yellow square (line) denotes the intensity of the observed event at Livingston, LA.

this data set, the return time for an event like the one in 2016 anywhere on the central US Gulf Coast is currently between 9 and 200 years (best estimate is 25 years). This is about a factor of 5 (CI 1.1-60) larger than it was around 1948, which equates to an increase in intensity for an event like the one in 2016 of roughly $15 \%$ (CI $0.4-30 \%$ ).

As for station data, analyses of CPC similar to the ones above but for the season JAS show somewhat smaller trends but with larger error margins. The estimated ranges of the JAS analyses and the all-year analyses overlap.

\subsection{Influence of natural variability}

We investigate the influence of natural variability on the probability of an event like the one in south Louisiana in 2016 by using indices of detrended SST as covariates in the time-dependent GEV fits. We first examine the influence of ENSO by using as a covariate a 6-month lagged Niño 3.4 index $\left(5^{\circ} \mathrm{S}-5^{\circ} \mathrm{N}, 170-120^{\circ} \mathrm{W}\right)$ minus SST averaged of $30^{\circ} \mathrm{S}-30^{\circ} \mathrm{N}$ to remove to first order the effects of global warming. This is inspired by the heavy rain events after the 1997/1998 El Niño event. A comparison of recent Niño 3.4 conditions with those from a year following the strongest $\mathrm{La}$ Niña year (1917) in a fit of all 324 stations with more than 10 years of data suggests that anomalously warm tropical Pacific SSTs significantly $(p<0.1)$ increase the probability of an event like the one in south Louisiana in 2016 but not by much. In the year after El Niño, the probability is a factor of 1.3 (CI 1.0-1.9) higher than in a year following a very strong La Niña. However, the maximum of stations with at least 80 years, which represents the largest events, does not show a signal, albeit with a large uncertainty of a factor of 0.5 decrease to a factor of 1.7 increase.

Simultaneous correlations with global SSTs indicate a region in the North Atlantic that has a significant relationship with central US Gulf Coast extreme precipitation at $p<0.1$
(Fig. 6). Although the field significance is very low, the region is a well-known source of decadal variability and predictability (e.g., Hazeleger et al., 2013), so we still consider it a possible source of decadal variability of extreme precipitation. We use an area average of SSTs between $45-60^{\circ} \mathrm{N}$ and $50-20^{\circ} \mathrm{W}$ as a covariate in the GEV fit. The region was anomalously cold in 2016, so we compare the changed probability with a warm year (2006). In this statistical analysis, North Atlantic SSTs are significantly correlated $(p<0.01)$ to central US Gulf Coast precipitation (by design, as we chose the region that has a significant correlation), with recent below-average SSTs decreasing the probability of an event like the one in 2016 (risk factor 0.37, CI 0.11-0.81). To ascertain whether this is a physical connection and not just a coincidence by picking the region of largest correlations, we need to analyze model results.

\section{Model evaluation}

We here describe an evaluation of simulated precipitation extremes in the two global coupled models (model descriptions in Sect. 2.2). Precipitation is a notoriously difficult field to simulate, as many coupled climate models exhibit large biases (Dai, 2006; Flato et al., 2013). Though FLORFA and HiFLOR underestimate the intensity of central US Gulf Coast precipitation extremes slightly, this bias is significantly reduced in these high-resolution models compared to standard-resolution models (Van der Wiel et al., 2016).

\subsection{Annual cycle and intensity}

First we analyze the annual cycle of extreme precipitation intensity. We consider the median and 97.5 percentile of the monthly maximum of the spatial maximum of 3-day averaged precipitation (Fig. 7). The 97.5 percentile events are of 

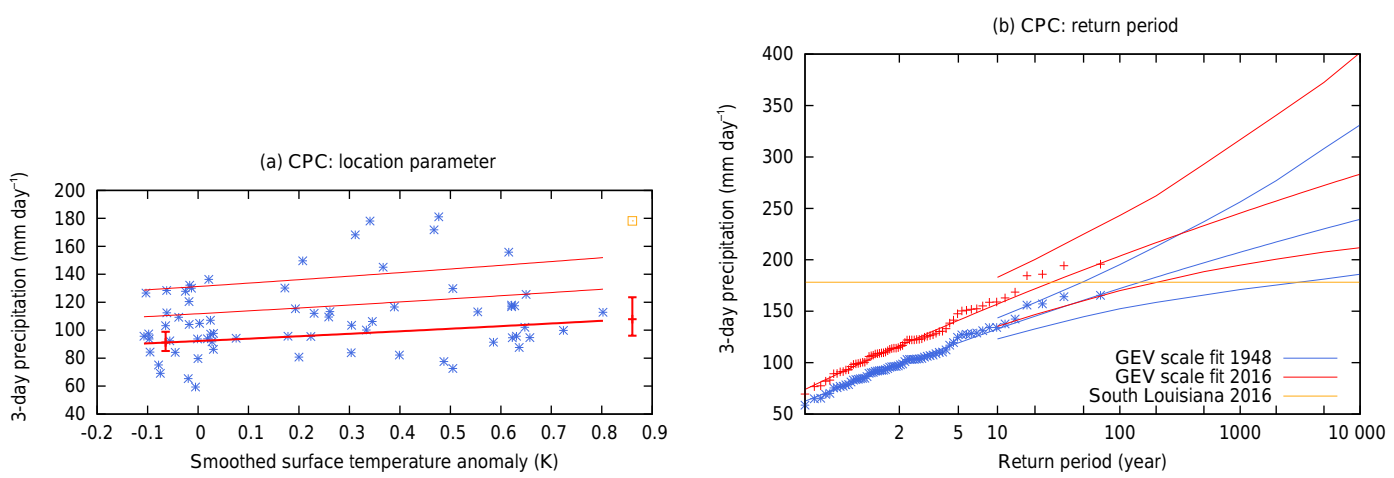

Figure 5. The same as Fig. 4 but for the spatial and annual maximum 3-day average of $1948-20160.25^{\circ} \times 0.25^{\circ}$ gridded CPC analysis

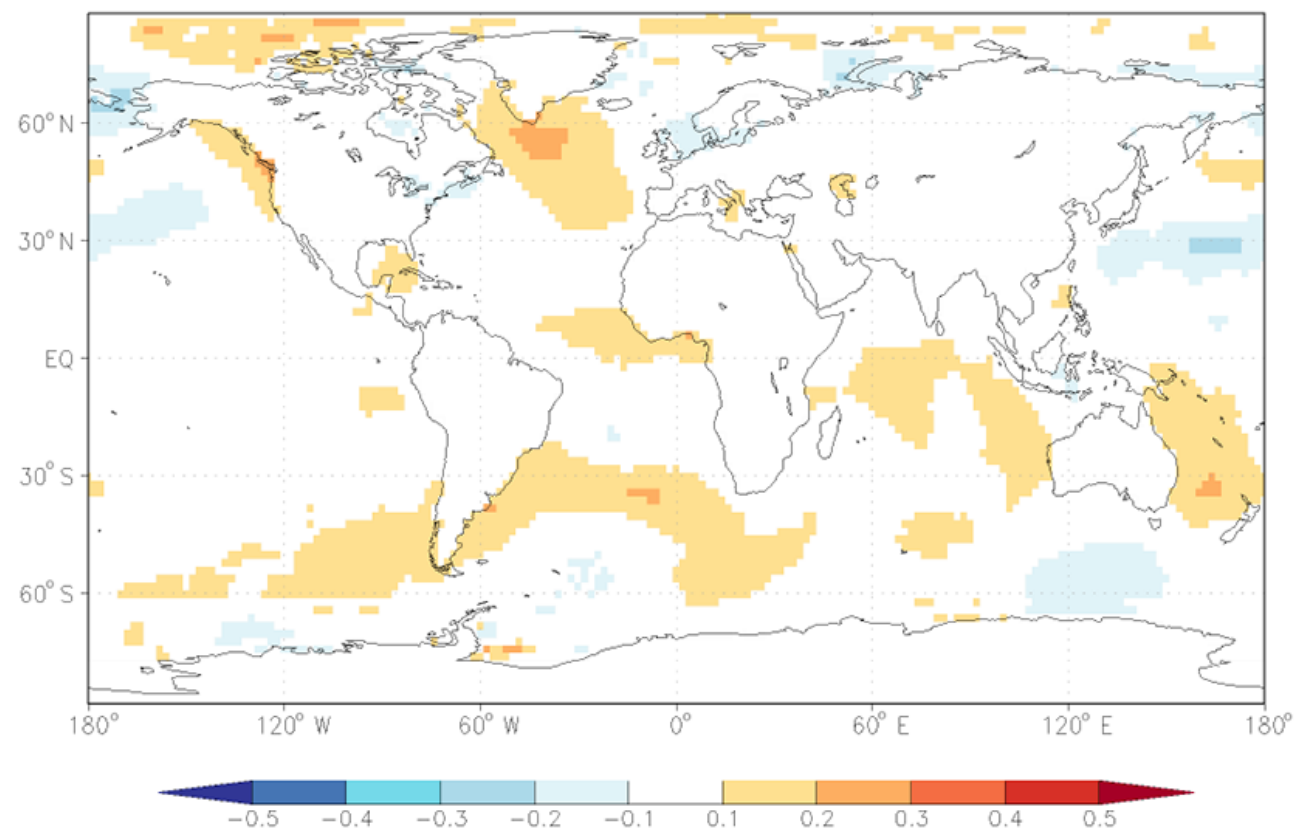

Figure 6. Correlation coefficient between central US Gulf Coast spatial and annual maximum of 3-day extreme precipitation intensity and annual mean SST (ERSST v4) with a linear regression on the global mean temperature removed at each grid point.

smaller magnitude than the south Louisiana observed event (100-150 $\mathrm{mm} \mathrm{day}^{-1}$ versus $\left.200 \mathrm{~mm} \mathrm{day}^{-1}\right)$, but we consider smaller magnitude events to increase the number of events in the calculation and hence decrease uncertainties.

The observed precipitation extremes in spring and summer are generally more intense than in autumn and winter (Fig. 7a). There is no agreement between the two observational products on which season sees the most intense precipitation extremes (97.5 percentile; Fig. 7b), though extremes in March-October are more intense than in winter. This period of stronger extremes is longer than the hurricane season, which provides a fraction of these extremes. In this region, the models underestimate the intensity of extreme precipitation, which was also noted in Van der Wiel et al. (2016). FLOR-FA has a peak season for extreme precipitation intensity in JAS which is not found in the observational data.
The HiFLOR SST-restored experiment, in which global SST biases are decreased compared to the free-running experiments, shows a similar peak in JAS. The HiFLOR 1990 static forcing experiment, however, does not show this peak. Instead, it has a similar annual cycle structure to the observational data, though with a smaller amplitude.

\subsection{Meteorological conditions}

Next, we investigate the meteorological conditions generating extreme precipitation events in both models and compare these to the observed ones. For this analysis, we consider the longest static forcing experiments for each model: 1860 for FLOR-FA and 1990 for HiFLOR and the CPC gridded precipitation analysis. The selection of these events is limited to 


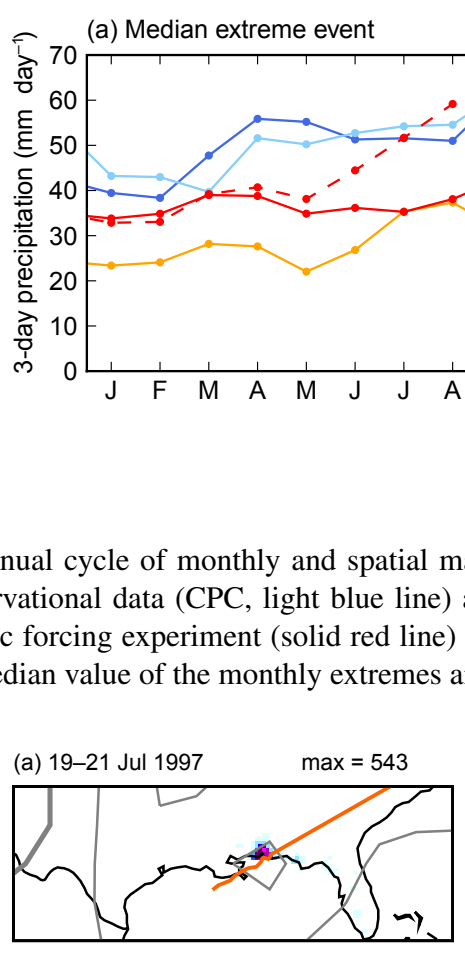

(d) 1-3 Sep $2008 \quad \max =467$

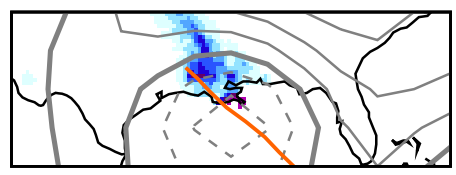

(g) 25-27 Jul $1979 \quad \max =390$

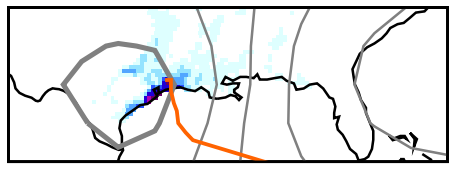

(b) 12-14 Aug 2016

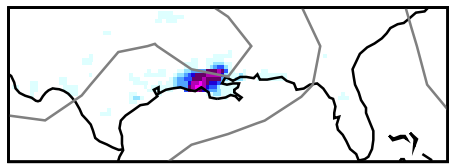

(e) 10-12 Sep 1961

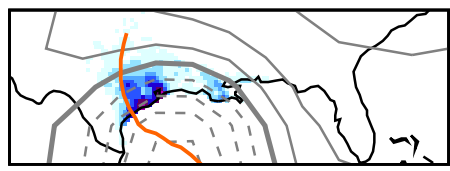

(h) 29-31 Jul $1975 \quad \max =390$

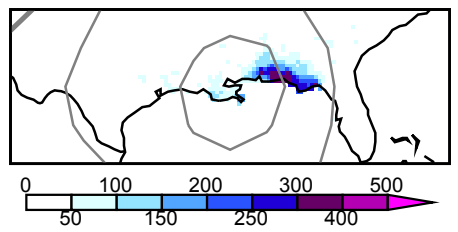

(c) 27-29 Sep $1998 \quad \max =516$

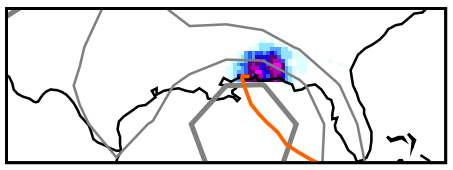

(f) 16-18 Sep $1963 \quad \max =397$

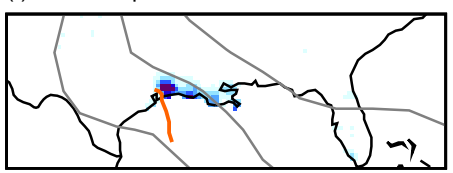

(i) $17-19$ Sep $1957 \quad \max =385$

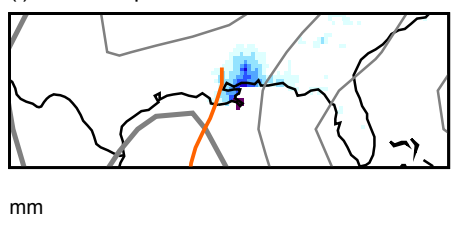

Figure 8. Top nine extreme precipitation events in the central US Gulf Coast $\left(29-31^{\circ} \mathrm{N}, 85-95^{\circ} \mathrm{W}\right)$ for the CPC gridded precipitation analysis. The 3-day precipitation sum (millimeters, shaded colors, as in Fig. 1d), $850 \mathrm{hPa}$ height for the middle day (grey contours, interval $25 \mathrm{~m}, 1500 \mathrm{~m}$ contour thickened, lower contours dashed) from NCEP/NCAR Reanalysis 1 (Kalnay et al., 1996) and tropical cyclone track if system is classified as a tropical cyclone (orange line, IBTrACS). These extreme events are calculated for the 3-month period JAS.

the region of interest (central US Gulf Coast) and the months JAS to facilitate comparison to the south Louisiana event.

Precipitation totals and circulation patterns for the nine largest extreme precipitation events in the CPC analysis (JAS season only) are shown in Fig. 8. Note that the 2016 south Louisiana event ranks as number 2; heavy precipitation related to Hurricane Danny in 1997 was stronger, though it was confined to a smaller area. Seven of these nine events were associated with a tropical cyclone/hurricane making landfall (78\%, orange tracks are the International Best Track Archive for Climate Stewardship, IBTrACS, track estimate; Knapp et al., 2010); the exceptions are July 1975 and, as noted before, August 2016. Note that the GEV analysis in Sect. 3.2 was based on annual maxima, for which the ranked extreme events are different than the ones shown in Fig. 8 (these are 9 of the top 14 events when all data are taken into account; ranks 1 and 2 are the same).

A similar figure for FLOR-FA is included in Fig. 9. We now show the 18 most extreme events (approximate return period $3530 / 18 \approx 200$ years) in FLOR-FA. The return period in the model for these events is much larger than the return period for the observed events in the CPC analysis (approximate return period $69 / 9 \approx 8$ years). Despite the negative bias of precipitation extreme intensity (Sect. 4.1), the precipitation sums for these events are therefore larger than those in the observed data. All events are associated with a low pressure system, of which eight (44\%, orange tracks in Fig. 9) are tropical cyclones based on the tropical cyclone tracking 

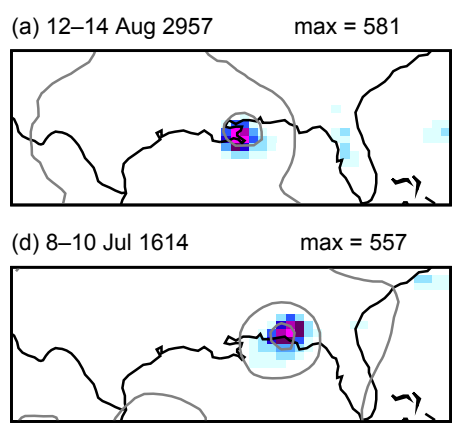

(g) 13-15 Aug 1136
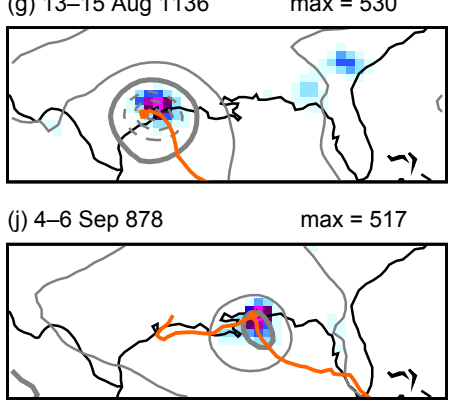

(m) 10-12 Jul $587 \quad \max =508$

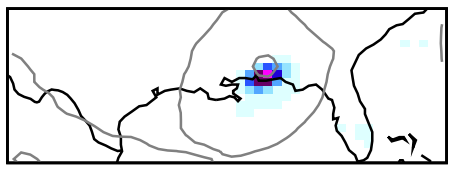

(p) 20-22 Sep 3219

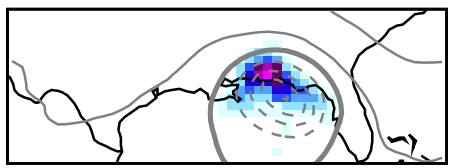

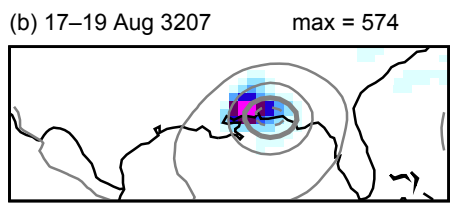

(e) 19-21 Aug $228 \quad \max =553$

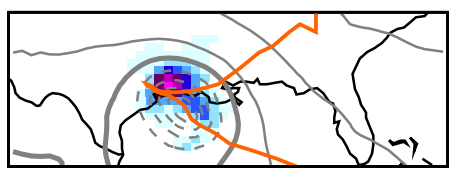

(h) 26-28 Jul 572

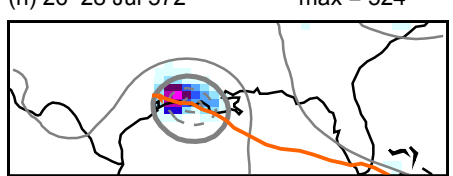

(k) 21-23 Aug 749 $\max =509$

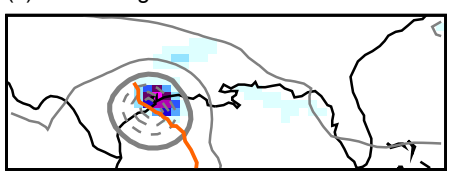

(n) 13-15 Aug $889 \quad \max =506$

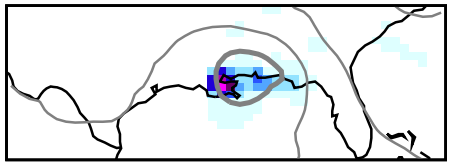

(q) 18-20 Jul $938 \quad \max =503$

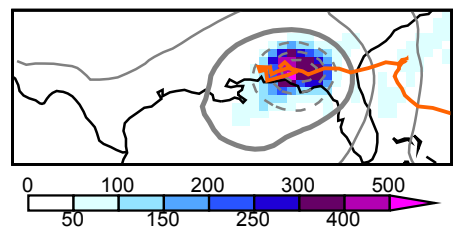

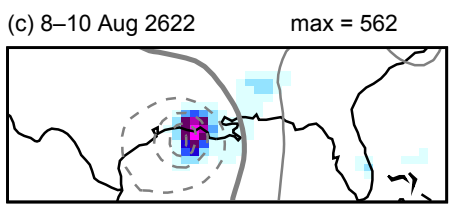

(f) 21-23 Sep $1922 \quad \max =534$

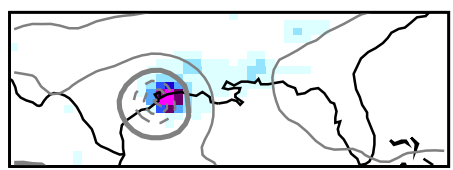

(i) 18-20 Jul $2941 \quad \max =522$

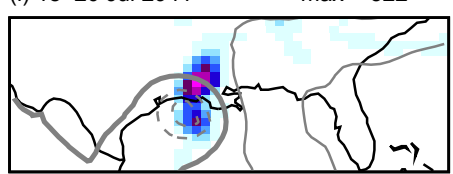

(I) 29-31 Jul $1520 \quad \max =508$

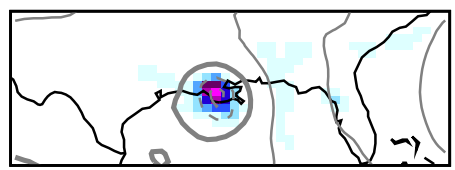

(o) 20-22 Aug $417 \quad \max =503$

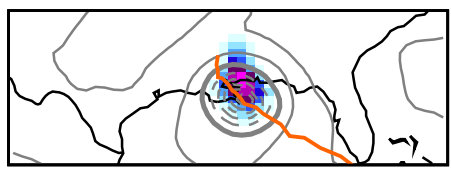

(r) 28-30 Jul 524 $\max =499$

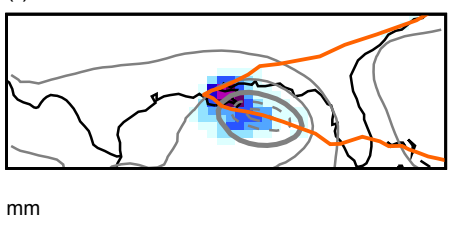

Figure 9. The same as Fig. 8 but for the top 18 maximum extreme precipitation events in the 1860 FLOR-FA static forcing experiment. Note that years are model years and do not resemble dates on the real-world calendar and that the model provides precipitation information over ocean grid boxes too.

methodology of Harris et al. (2016) as implemented in Murakami et al. (2015). Note that the low pressure systems of the top four events do not classify as tropical cyclones, showing the precipitation potential of non-tropical cyclone low pressure systems in the model.

Because the HiFLOR 1990 static forcing experiment is of smaller length, it is not possible to sample the 200-year return period event, as was done for FLOR-FA, adequately. In Fig. 10, we show the six most extreme events (approximate return period $280 / 6 \approx 50$ years; the top two events are samples of events with return periods of about 150 years). In HiFLOR, the most extreme precipitation events are the result of a tropical cyclone, though storm intensity (storms in Fig. 10a, $\mathrm{b}$ are tropical storms; storms in Fig. 10c, d are hurricanes at the time of landfall) is not related to resulting precipitation magnitude. Note that the strongest event in HiFLOR exceeds
$900 \mathrm{~mm}$ over a 3-day period, which is much stronger than the observed values in south Louisiana.

In conclusion, though the precipitation extremes are of smaller magnitude in both models and the annual cycle in observations is not recovered well (Sect. 4.1), the meteorological system leading to these precipitation extremes in JAS are realistic and resemble observed systems (Sect. 4.2).

\section{Model analysis}

In order to attribute the observed trend to external forcing, we use global climate models that isolate the different forcings. The model and experimental description can be found in Sect. 2.2. 

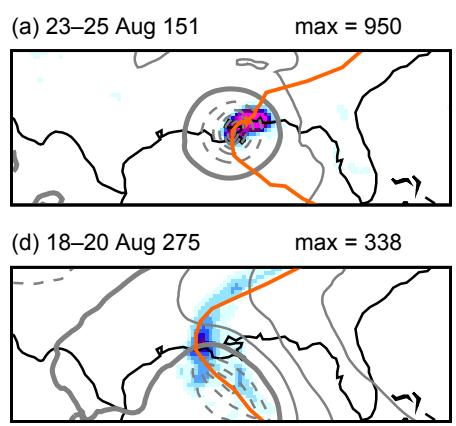

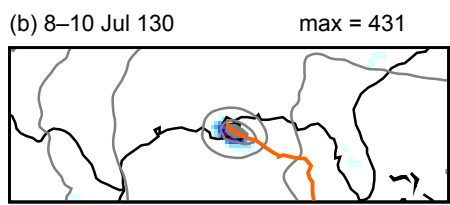

(e) 2-4 Jul 157

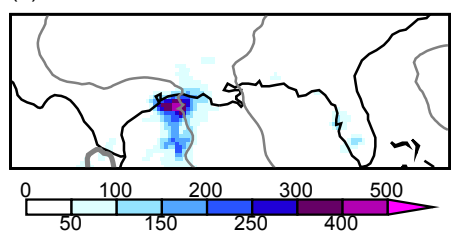

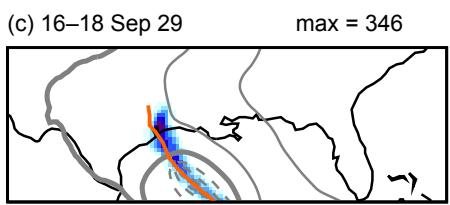

(f) 30 Aug-1 Sep $32 \quad \max =333$

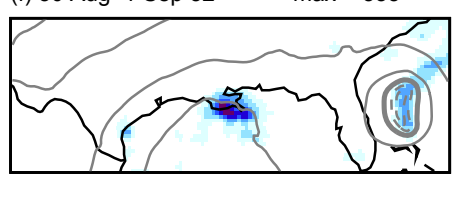

Figure 10. The same as Fig. 8 but now for the top six maximum extreme precipitation events in the 1990 HiFLOR static forcing experiment. Note that years are model years and do not resemble dates on the real-world calendar and that the model provides precipitation information over ocean grid boxes too.

\subsection{FLOR-FA}

A fit of all land grid boxes $\left(0.5^{\circ} \times 0.5^{\circ}, 23095\right.$ data points $)$ to a time-dependent GEV distribution is shown in Fig. 11. The uncertainties take into account the dependencies by moving spatial blocks of 7.7 grid points on average. In contrast to the observations (Fig. 3), the distribution cannot be described with a single GEV function: the extremes with return times larger than about 100 years $\left(80 \mathrm{~mm} \mathrm{day}^{-1}\right)$ diverge from the fit that is determined mainly by the less extreme precipitation events. This so-called "double population" problem results from different meteorological mechanisms for extreme events. We therefore cannot use this fit for attribution.

Taking the spatial maximum of all grid boxes selects only the high end of the distribution. Figure 12a, c show the GEV fit to these extremes using data for simulated years 18612015. The fit is still not completely satisfactory as the highest five events (all in the early years of the experiments) fall on the upper boundary of the $95 \% \mathrm{CI}$ around the fit to the rest of the distribution. Due to this, the shape parameter $\xi$ and scale parameter $\sigma$ of the GEV distribution are higher than they are in the observations. Because of model bias, we define our event to have the same return period as the gridded observations in 2016 (around 30 years, $115 \mathrm{~mm} \mathrm{day}^{-1}$ ). This gives a trend in this model that is significantly greater than zero at $p<0.05$ (one-sided). However, the factor of 1.3 (CI 1.0-1.9) increase in probability, corresponding to an increase in intensity of $5 \%(\mathrm{CI}-1-14 \%)$, is much less than the observed one.

Assuming that the relationship with global mean surface temperature does not change in the model world up to 2100 , in spite of a different mix of anthropogenic forcings (greenhouse gases and aerosols), we can improve the signal-tonoise ratio of the fit by using all data in the variable forcing experiment (Fig. 12b, d). For the spatial and annual maximum of 3-day averaged precipitation, this gives an increase in probability of a factor of 1.8 (CI 1.4-2.0) corresponding to an increase in intensity of $11 \%$ (CI 7-12\%) up to now.
Analogous analyses but for the season JAS show similar results, although with larger error margins. We looked for an effect of ENSO in the long static forcing experiment in the same way as in the observations. This does not show any influence of El Niño averaged over the 12 months of JulyJune preceding the year of extreme precipitation events.

\subsection{HiFLOR}

The HiFLOR model at a higher $25 \mathrm{~km}$ resolution has a more realistic seasonal cycle but underestimates extreme precipitation by $25 \%$ for a 1 -in-1-year event and by $35 \%$ for 1 -in1000 -year extremes. We correct for this bias as we did for the FLOR-FA experiment (the 30 -year event is $103 \mathrm{~mm} \mathrm{day}^{-1}$ ). We concatenated the four static forcing experiments that we have available, leaving out the first 20 years of each, to create a 655-year record. To decrease dependencies, we averaged $2 \times 2$ grid boxes into a $0.5^{\circ}$ grid; this results in each grid box being correlated with 10.3 others with $r>1 / e$ on average.

As was found for FLOR-FA, the GEV fit to all grid points results in a double population; therefore, we disregard that analysis and instead focus on the spatial maximum precipitation extreme. Similar for FLOR-FA, taking the spatial maximum of this $50 \mathrm{~km}$ data set selects mainly events in the more extreme population and does give a good fit to the GEV distribution (Fig. 13). The outlier event is a tropical cyclone in the 1990 static forcing event that was discussed in Sect. 4.2 (Fig. 10a). The external forcing, which is the only change between the static forcing experiments, causes an increase in probability of a $103 \mathrm{~mm}$ or stronger event of a factor of 2.0 (CI 1.4-2.5), in agreement with the FLOR-FA experiment up to 2100 (Fig. 12b, d). This corresponds to an increase in intensity of $10 \%$ (CI 5-12\%).

An analysis of these data, using the annual averaged detrended Niño 3.4 index lagged by 6 months as a covariate, shows a relatively strong influence of El Niño in this model, with an increase in probability from the year follow- 

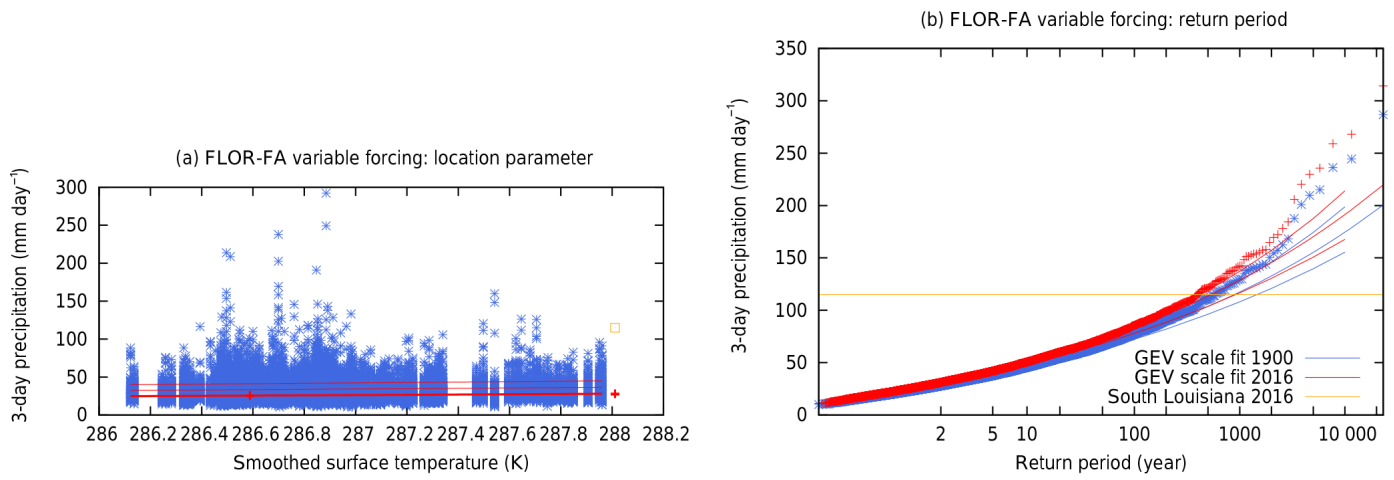

Figure 11. The same as Fig. 4 but for the annual maximum 3-day average precipitation in the FLOR-FA variable forcing experiment (based on the complete experiment, 1861-2100).
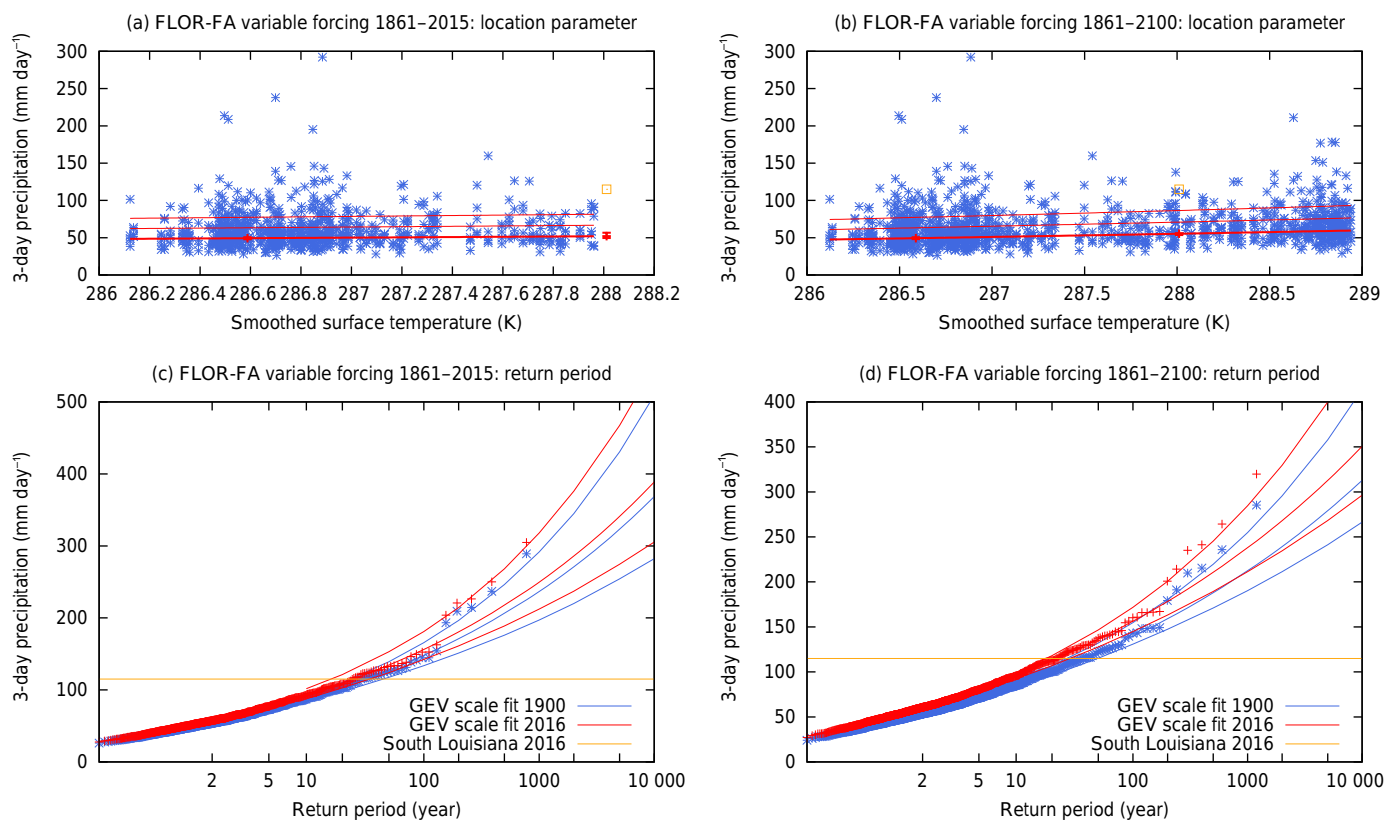

Figure 12. The same as Fig. 4 but for the annual and spatial maximum 3-day average precipitation in the FLOR-FA variable forcing experiment, with (a, c) taking into account years 1861-2015 and (b, d) taking into account 1861-2100.

ing strongest La Niña to the strongest El Niño of a factor of about 4.2 (CI 1.7-6.7).

We followed the same procedure on the six ensemble members of the variable forcing HiFLOR experiment (19712015). These simulations do not have a negative bias in extreme precipitation. The restored SSTs eliminate a $2 \mathrm{~K}$ cold bias in the subtropical Atlantic that is present in the static forcing experiments, which may have caused the bias in precipitation extremes on the central US Gulf Coast in those simulations. Again there is one outlier event with $452.8 \mathrm{~mm} \mathrm{day}^{-1}$ over 3 days ( $1351 \mathrm{~mm}$ total).

The spatial and annual maximum of 3-day averaged extreme precipitation increases by a factor of 1.8 (CI 1.2-3.3) in these experiments over the period 1971-2015, corresponding to a change in intensity of $14 \%$ (CI 4-27\%; Fig. 14).
Although the restoring of SSTs increases the fidelity of the simulation, it also includes the non-forced natural variability of the real world, so these numbers do not isolate the forced change but show the full change including the effects of natural variability. Assuming these are small compared to the trend, we can extrapolate to the full change since 1900; the period 1971-2015 only includes about two-thirds of global warming since pre-industrial times. This translates to a factor of 2.4 (CI 1.3-6) increase in probability and $22 \%$ (CI 6$41 \%$ ) in intensity, which is very similar to the trend found in the observational data.

Analyses of the season JAS show similar to somewhat smaller trends, but with larger error margins, overlapping the all-year error margins. 

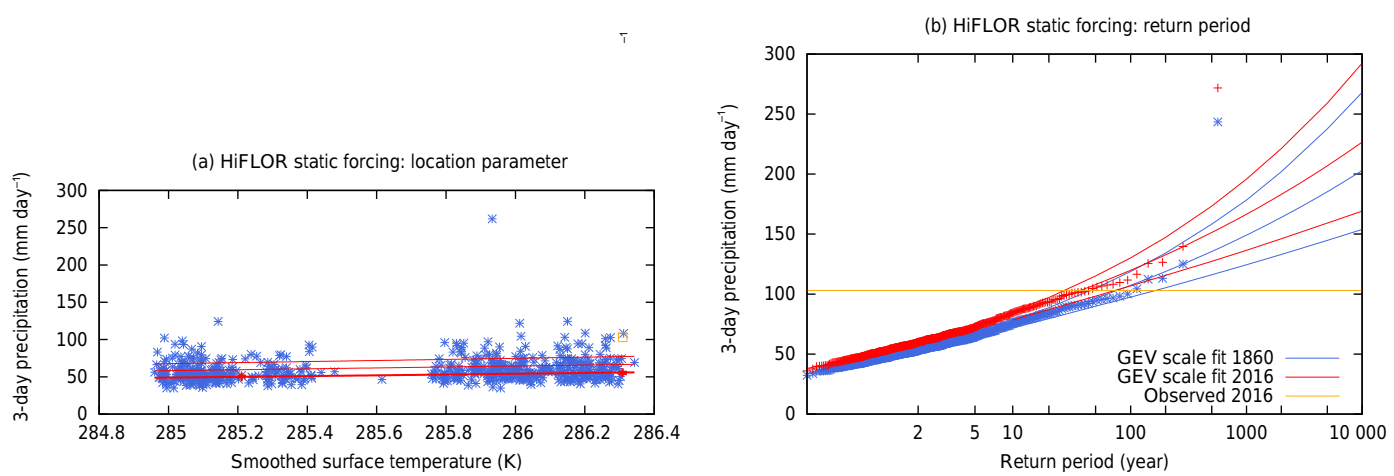

Figure 13. The same as Fig. 4 but for the annual and spatial maximum 3-day average precipitation in the HiFLOR static forcing experiments.
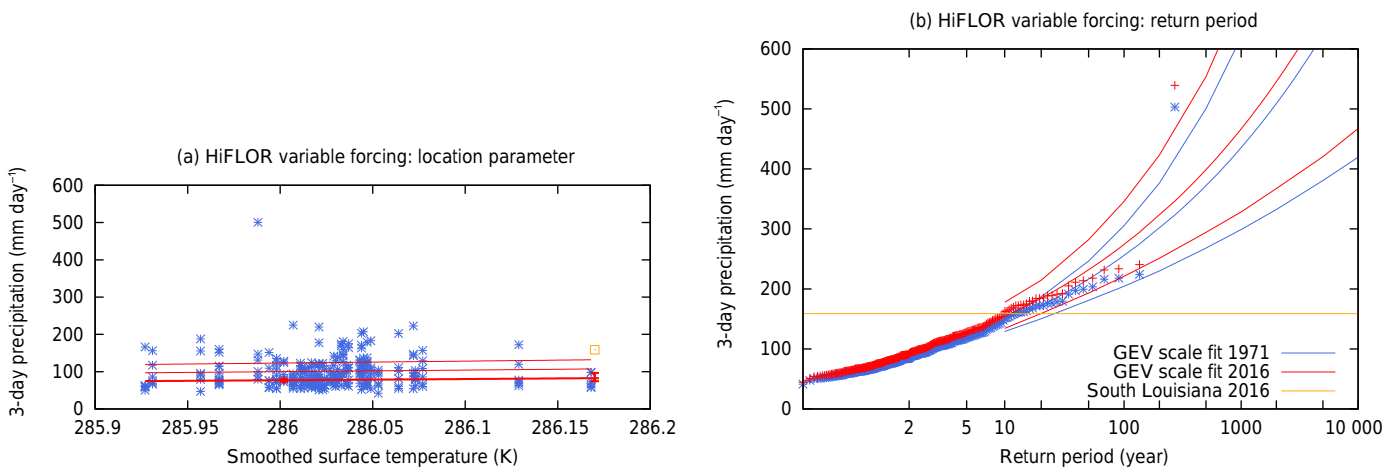

Figure 14. The same as Fig. 4 but for the annual and spatial maximum 3-day average precipitation in the HiFLOR variable forcing restored SST experiments.

\section{Summary}

In this section, we summarize the principal observational and model-based results as described in Sects. 3 and 5. We have analyzed two observational data products (GHCN-D point station data and CPC $0.25^{\circ} \times 0.25^{\circ}$ gridded analysis), to estimate the probability and changes in probability and intensity of a 3-day precipitation event as large as that observed in south Louisiana in 2016. The analysis was confined to the central US Gulf Coast $\left(29-31^{\circ} \mathrm{N}, 85-95^{\circ} \mathrm{W}\right)$ and relied on time-dependent GEV fits to the data. First, we investigated probabilities and changes at a single station, i.e., the probability of such an event at a fixed place in the region. Second, we investigated regional probabilities and changes, i.e., the probability of such an event anywhere in the region. The spatial scale of the most extreme precipitation events is significantly smaller than the region considered; therefore, the second probability is lower than the first. To attribute the observed changes to forced anthropogenic climate change, we repeat the analysis using high-resolution global climate model data from GFDL FLOR-FA and GFDL HiFLOR. GEV fits for the local analysis were unsatisfactory; therefore, we only report the regional change in probabilities.
The expected return period of a comparable 3-day precipitation event at a single station as high as the maximum observed is 450 to 1450 years (best estimate is 550 years). Return periods like these are often written as a 1-in-1000-year event. The return time for observing an event anywhere in the region is lower: between 11 and 110 years (best estimate is 30 years). All observational analyses found clear positive trends, with an increase in probability for the regional event of about a factor of $6.3(97.5 \%$ certain more than 2.1$)$ and an increase in intensity of 12 to $35 \%$ (Table 3 ). Estimates based on CPC gridded data are comparable but have larger ranges due to the shorter period of data availability.

The sensitivity of precipitation extremes from both models is consistent with that estimated from the gridded observations. The lower-resolution FLOR-FA model shows lower trends than the HiFLOR model. For the HiFLOR model, the sensitivity estimated from the SST-restored experiment for 1971-2015 is larger than that from the coupled simulations. Taking into account all modeling results, the probability of an event like the one in south Louisiana in 2016 has increased at least by a factor of 1.4 due to radiative forcing; the two HiFLOR experiments and the analysis of the full data set from FLOR-FA suggest central values close to a doubling of probability. Such an increase in probability may be explained as follows: what used to be an event with a return 
Table 3. Summary of observed (first two rows) and modeled (third row and down) changes in regional rainfall extremes in the central US Gulf Coast. Note that the modeled changes can be attributed to anthropogenic climate change.

\begin{tabular}{|c|c|c|c|c|}
\hline Data source (years used for calibration) & $\begin{array}{l}\text { Baseline regional return } \\
\text { period for } 2016 \text { event } \\
\text { (95\% confidence range, } \\
\text { observations only) }\end{array}$ & $\begin{array}{r}\text { Years change } \\
\text { calculated } \\
\text { over }\end{array}$ & $\begin{array}{r}\text { Change of return period } \\
\text { in present day over } \\
\text { given years (95\% } \\
\text { confidence range) }\end{array}$ & $\begin{array}{r}\text { Change in intensity of regional } \\
30 \text {-year return event in } 2016 \\
\text { since beginning of record } \\
(95 \% \text { confidence range })\end{array}$ \\
\hline GHCN-D rain gauges, minimum 80-year data (1930-2016) & 30 years $(11 \ldots 110)$ & 1930-2016 & $6.3 \times(2.1 \ldots 50)$ & $+25 \%(12 \% \ldots 35 \%)$ \\
\hline $\mathrm{CPC} 0.25^{\circ} \times 0.25^{\circ}$ gridded data $(1948-2016)$ & 25 years $(9 \ldots 200)$ & $1948-2016$ & $5.4 \times(1.1 \ldots 60)$ & $+15 \%(0.4 \% \ldots 30 \%)$ \\
\hline FLOR-FA variable forcing experiment (1861-2015) & & 1900-2016 & $1.3 \times(1.0 \ldots 1.9)$ & $+5 \%(-0.5 \ldots 14 \%)$ \\
\hline FLOR-FA variable forcing experiment (1861-2100) & & 1900-2016 & $1.8 \times(1.4 \ldots 2.0)$ & $+11 \%(7 \% \ldots 12 \%)$ \\
\hline HiFLOR static forcing experiment $(1860,1940,1990,2015)$ & & $1860-2015$ & $2.0 \times(1.4 \ldots 2.5)$ & $+10 \%(5 \% \ldots 12 \%)$ \\
\hline $\begin{array}{l}\text { HiFLOR variable forcing experiment (1971-2015), } \\
\text { extrapolated to } 1900-2015\end{array}$ & & $1900-2015$ & $2.4 \times(1.3 \ldots 8)$ & $+22 \%(6 \% \ldots 41 \%)$ \\
\hline
\end{tabular}

time of 100 years should now be expected to occur, on average, once every 70 years or likely even more frequently. This trend is expected to continue over the 21 st century as past and projected future greenhouse forcing continues to warm the planet.

The evidence for an influence of the strong 2015/2016 El Niño increasing the probability of the 2016 event is equivocal. The full station data set shows a statistically significant but small increase in probability, but we do not find the same for the spatial maximum, which represents the strongest events. The FLOR-FA model similarly does not have an ENSO effect, whereas the HiFLOR model again shows a higher probability after a large El Niño. We have found some evidence for decadal Atlantic variability affecting precipitation in the observations, which would have decreased the likelihood in 2016 if confirmed.

\section{Discussion}

We have presented a rapid attribution to climate change and climate variability of the south Louisiana intense precipitation event. Here, we lay out the crucial assumptions made to conduct our assessment, further lines of inquiry to investigate the validity of the crucial assumptions and the sensitivity of our results to changes in these assumptions, suggestions for further study on related topics not investigated here and questions that arise from this work. Finally, we note some societal impacts of the findings.

\subsection{Crucial assumptions}

In performing these analyses, we have made the following crucial assumptions about the statistical distribution of precipitation extremes, the observations, the relationship between temperature and precipitation extremes and the models. We have tested the sensitivity of our results to some of these assumptions in the results sections (Sects. 3-5) and discuss them below.

1. We assume that the local annual maxima of 3-day averaged precipitation over the region of analysis (29- $\left.31^{\circ} \mathrm{N}, 85-95^{\circ} \mathrm{W}\right)$ can be grouped together and that their statistical distribution follows a GEV distribution. Underlying this is the assumption that the region has homogeneous extreme precipitation characteristics (Fig. 1f). Furthermore, we assume that all the annual maxima of 3-day averaged precipitation are drawn from the same statistical distribution, in spite of the many different mechanisms that led to extreme precipitation in this region, and that this distribution can be represented well by a GEV distribution. We further assume that the spatial maximum over the region can also be described by a GEV.

2. We assume that analyzing all seasons together provides a fuller distribution of the population of extreme precipitation events than isolating the analysis to seasons proximate to August (the month in which the south Louisiana event occurred). In part, the choice to analyze annual extreme events was motivated by the fact that a variety of meteorological phenomena can lead to extreme precipitation in this region, flooding can occur in any season and precipitation extremes may change in various seasons (Lehmann et al., 2015; Van der Wiel et al., 2016). All extreme value analyses were repeated focusing only on the JAS season and the qualitative nature of the results was the same as those presented.

3. We assume that the inhomogeneities in point station data due to station changes, incomplete records and geographic coverage are smaller than the trends and have no coherent sign. We have checked this by performing the analysis on all stations and for a subset of stations with long (at least 80 -year) records and sufficient $\left(0.5^{\circ}\right)$ spatial separation.

4. We assume that the methods that create the gridded observationally based precipitation data result in an accurate representation of 3-day average precipitation at the grid scale. The decorrelation scale of 3-day precipitation is about twice the grid scale, so the largest uncertainty is the inhomogeneous distribution of the gauge stations in 
(a) Change in probability preindustrial to present

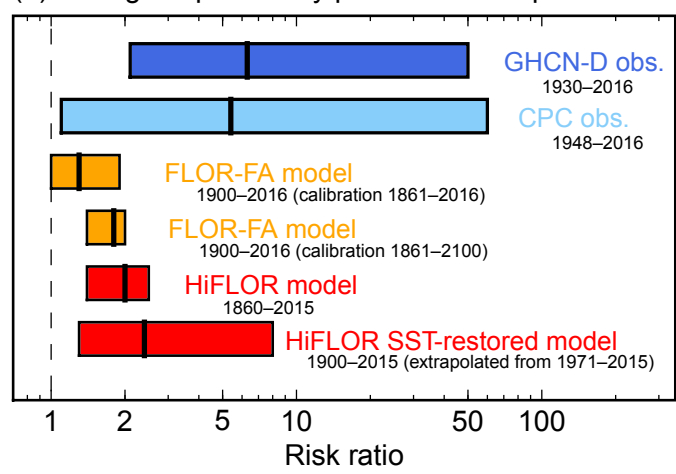

(b) Change in intensity preindustrial to present

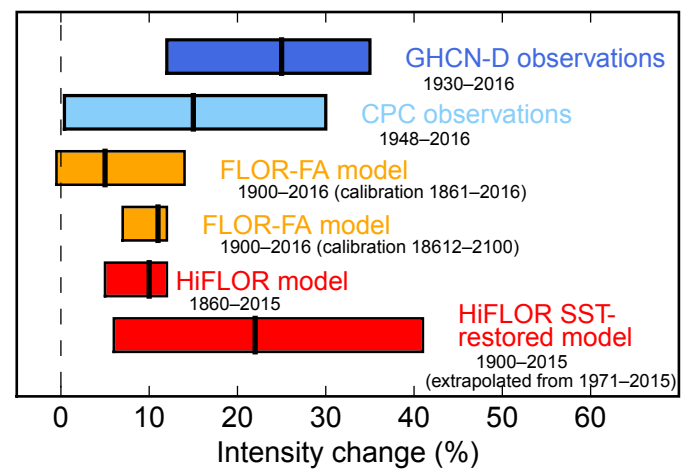

Figure 15. Summary of observed (GHCN-D, CPC, blue colors) and modeled (FLOR-FA, HiFLOR, yellow, red color) changes in regional precipitation extremes in the central US Gulf Coast. Ranges written in black are the time periods for which the change is shown over. Calibration for the calculations is done over separate time periods for noted models. See Table 3 for specific numeric values.

space and time. A comparison of the results with point station data shows that the differences are not large.

5. We assume that, for the assessment of trends in GEV statistics, global mean surface temperature represents a relevant covariate to capture the a priori expected connection between precipitation extremes and temperature (e.g., O'Gorman, 2015). A physical motivation for this expected connection is the dependence of the saturation-specific humidity of air on temperature through Clausius-Clapeyron (see Sect. 1). The underlying assumption is that multidecadal temperature changes exhibit "pattern scaling", such that global mean temperature change is a sufficient parameter to describe the long-term changes of temperature; furthermore, global mean temperature helps increase the signal-to-noise ratio of fits to temperature changes. If there is substantial spatial heterogeneity to temperature changes on multidecadal timescales, the assumption that global mean temperature is the relevant metric becomes suboptimal. Furthermore, if dynamical changes (changes in the statistics of storms, changes in the dominant moisture sources for extremes, etc.) dominate the observed multidecadal precipitation extreme changes, this assumption will also be suboptimal.

6. We assume that the probability density function of precipitation extremes scales with a covariate, for example, (smoothed) global mean temperature, and does not exhibit other changes in shape. This assumption is supported by large-sample statistics from modeling experiments such as Weather@Home (Massey et al., 2015) in other regions, but it is not a priori obvious that these results should also hold for the central US Gulf Coast with its wide variety of weather phenomena causing extreme precipitation. Furthermore, the Massey et al. (2015) results were from models of resolution too low to resolve many of the meteorological phenomena that led to ex- treme precipitation (e.g., tropical cyclones) in this region.

7. We assume that, beyond an initial rapid ( 20-year) adjustment to different static radiative forcings, the statistics of precipitation extremes in the static forcing model experiments depend on global mean temperature in the same way as the changes arising from slow drift due to top-of-the-atmosphere radiative disequilibria and slow ocean adjustment. The latter changes are smaller than the forced trend, so the impact of slow model drift on the results is small.

8. We assume that the CMIP5 historical forcings (18602005) and RCP4.5 forcings (2005-2100), as implemented in the models, are sufficiently accurate representations of the actual changes in radiative forcing that occurred in the real climate system to allow meaningful comparison of modeled changes in precipitation extremes to those observed.

9. We assume that the FLOR-FA and HiFLOR modeled responses to changes in radiative forcing are meaningful estimates of the sensitivity of precipitation extremes in the real climate system, since these models capture multiple physical factors affecting precipitation extremes in a physically based and internally consistent framework. This assumption is motivated in part because of the ability of these models to simulate large-scale precipitation and temperature over land (e.g., Van der Wiel et al., 2016; Delworth et al., 2015; Jia et al., 2015, 2016), precipitation extremes over the US (Van der Wiel et al., 2016), modes of climate variability (e.g., Vecchi et al., 2014; Murakami et al., 2015), the meteorological phenomena that led to precipitation extremes and their relationship to modes of climate variability (e.g., Vecchi et al., 2014; Krishnamurthy et al., 2015; Murakami et al., 2015, 2016; Zhang et al., 2015, 2016; Pascale et al., 
2016), and that these models show skill at seasonal predictions of large-scale climate, regional hydrometeorology and the statistics of weather extremes across a broad range of climatic regimes (e.g., Vecchi et al., 2014; Jia et al., 2015, 2016; Yang et al., 2015; Msadek et al., 2014; Murakami et al., 2015, 2016). However, it is important to note that climate models can show a range of global and regional climate sensitivities to changing radiative forcing (e.g., Kirtman et al., 2013; Collins et al., 2013).

These assumptions were crucial to enable a rapid assessment of the climate context of the extreme precipitation of the August 2016 south Louisiana event. Subsequent analyses should further assess the validity of these assumptions and the quantitative impact of failures in their validity. Below we outline our present evaluation of the implications of these choices and potential areas of further research.

Sensitivity experiments should be produced by varying the parameters of our study. We did not conduct analysis of how the size of our defined box for the central US Gulf Coast affects our results (crucial assumption 1). If the region is altered to remove points that have greater risks relative to those included, the findings may change. Changes in extreme precipitation risks in the central US Gulf Coast should not be applied elsewhere without further investigation. Temporally, we were able to validate the seasonal distribution of precipitation extremes in models and observations (Sect. 4.1) and redid the analysis for JAS only, which gave larger uncertainties and somewhat smaller trends (crucial assumption 2). Future work could further quantify seasonal differences in extremes and their response to climate forcing. Similarly, to sample the spread in sensitivity to future RCP forcings (crucial assumption 8, used for any modeled years beyond 2005), our results may be revised with different climate forcings. For the near term, however, this is likely not an issue in HiFLOR (used to produce climates for 2005-2015 in the static forcing and nudged SST runs) as climate variability tends to be greater than the climate response to different scenarios during this time period (Forster et al., 2013; Hawkins and Sutton, 2009; Kirtman et al., 2013) but may affect future climate results in the FLOR-FA variable forcing experiment at the end of the century (in 2100; Hawkins and Sutton, 2009). Furthermore, the appropriateness of GEV fits in general should be tested (crucial assumptions 1 and 6).

Sensitivity experiments of our results to model bias and integration length (or length of the observed record) should be produced (crucial assumptions 3 and 7). Short records limit the reliability of the statistics of precipitation extremes. This is important for our model validation of the annual cycle of extremes (Sect. 4.1) and for the comparison of modeled and observed GEV fits (Sect. 5). The statistics of precipitation extremes in HiFLOR are closer to those observed than the statistics in FLOR-FA. However, we note that the model experiments with FLOR-FA are significantly longer and therefore provide better statistics of its (biased) climate than the experiments with HiFLOR or the observed record. It cannot thus be fully excluded that the double distribution of extremes in FLOR-FA or the large peak in JAS in extreme precipitation intensity is purely a result of model bias.

A portion of the beginning of the static forcing experiments have been disregarded to allow the model to spin up in response to radiative forcing. GEV fits were originally calculated by disregarding the first 10 years of data to allow for spinup but were extended to 20 years to provide the simulated climate more time to approach equilibrium (crucial assumption 7). The results are only altered slightly by this sensitivity test. Given the length of the available ensemble suite of static forcing experiments, disregarding more years in the beginning of the simulation would reduce our ability to sample extremes. With longer integrations of static forcing experiments and additional ensemble members, we would have more information to assess how model spinup may affect our results. Similarly, longer integrations would allow for an assessment of the impact of model drift due to ocean adjustment (crucial assumption 7).

The attribution to climate change presented here depends on our assumption that changes in precipitation extremes scale with global mean temperature and do not arise from changes in the shape of their underlying distribution (crucial assumptions 5 and 6). The thermodynamic basis of this assumption is based on a large body of research ( $\mathrm{O}^{\prime}$ Gorman, 2015); however, as noted before, there is a large variety of synoptic systems that may cause precipitation extremes in the Gulf Coast region. It is not obvious that possible impacts of changes in synoptic weather patterns scale with global mean temperatures. For example, the frequency, track location and/or intensity of tropical cyclones (responsible for seven out of the nine most extreme events in JAS related to tropical cyclones; Fig. 8) can each change in complex ways that need not scale with each other or global mean temperature (e.g., Vecchi and Soden 2007; Murakami and Wang, 2010; Emanuel and Sobel, 2013; Emanuel et al., 2013; Knutson et al., 2013; Vecchi et al., 2013; Walsh et al., 2015) and could cause changes to the statistics of extreme rainfall in the central US Gulf Coast. Further research must investigate what the impact of dynamic changes (e.g., frequency of occurrence of various synoptic systems, dominant moisture sources, precipitation efficiency) is on the presented trend of precipitation extremes.

To investigate the sensitivity of the results to the chosen observational data sets (both based on rain gauge measurements; crucial assumptions 3 and 4), we suggest repeating the current analysis with an independent observational estimate of current and historical precipitation along the Gulf Coast (e.g., estimates based on satellite data). Furthermore, though we use two global climate models (FLOR-FA and HiFLOR; crucial assumptions 7 and 9) and various experimental setups (static radiative forcing, time-varying radiative forcing and restoring observed SST variability), the models are part of the same NOAA/GFDL family. Consequently, they exhibit 
similar patterns of (surface temperature) bias and rely on the same parameterization schemes for precipitation. Further inquiry for understanding model-specific biases that may impact the results may still be warranted. For example, there is a North Atlantic cold bias in the models, thought to be connected in part to inadequate eddy parameterizations and a resulting cloud feedback (Delworth et al., 2006, 2012; Vecchi et al., 2014; Murakami et al., 2015). This may be the source of higher magnitudes of modeled extreme precipitation found due to climate variability in the HiFLOR restored SST experiments. An assessment using different climate models would therefore add value to allow for a sampling of risk across models, as well as across experimental setups. These will be available shortly in the HighResMIP project (Haarsma et al., 2016).

\subsection{Future work and broader impacts}

As described in the introduction and methods, we have purposefully focused our present assessment on one aspect of the flooding problem: the risk of extreme precipitation events that have the potential to produce inland flooding. We have provided provisional stream gauge data in the introduction (Fig. 2) to illustrate the effect of the August 2016 event but have not examined flood risks in the region from stream gauge data directly. Part of the reason for this is that real-time stream gauge data are provisional and subject to revision, which can be exacerbated during a flood when gauges can be overtopped and have missing data due to high water volumes or stream gauge malfunctions (Rantz, 1982). The USGS advises users to cautiously consider the use of provisional stream gauge data for decision making (official USGS provisional policy available at https://water.usgs.gov/wateralert/ provisional/). A complimentary modeling study of land surface conditions and interactions with the river environment also requires a more local modeling approach, potentially with a hydrologic model with information on the river system and small-scale water processes and conceivably including an estimate of the impact of direct human impacts (through urbanization, water diversion and management, etc.). Under our time constraints, data access and present capabilities of our climate models, this was presently was not feasible.

It is important to distinguish extreme precipitation events that are the topic of this study, motivated by the August 2016 rain event that led to devastating "freshwater" or "inland" flooding in south Louisiana, from events that led to "coastal" or "saltwater" flooding. In particular, the climate change context of saltwater flooding must include an assessment of the regional sea level change contributions and meteorological conditions that can influence these types of events (e.g., Katsman et al., 2008; Sterl et al., 2012; Lin et al., 2012, 2014; Little et al., 2015). While certain meteorological conditions, such as landfalling tropical cyclones, can lead to both freshwater and saltwater flooding (e.g., Lin et al., 2012; Villarini et al., 2014), the assessments and discussions presented here are only relevant to extreme rainfall events that have the potential to initiate inland flooding; we do not address changes in storm surges, nuisance flooding (Moftakhari et al., 2015) or other saltwater flooding events.

Dependence of the statics of extreme precipitation events in the central US Gulf Coast on large-scale climate drivers could provide a scientific basis for seasonal predictions of the odds of these events, much as is now regularly done for the statistics of hurricanes. However, as we show in Sect. 3.3, we are unable to find strong connections between the statistics of these extreme precipitation events and modes of SST variability (e.g., ENSO), which suggests the possibility for limited seasonal predictability for these events beyond the multidecadal increase in probability from long-term climate warming. However, potential sources of predictability may be uncovered by future refined analyses.

The extent to which the changing risk of extreme rainfall events like that in south Louisiana has implications for stakeholders, such as homeowners, local and federal governments, the humanitarian system and the insurance industry, will depend on details of the exposure, vulnerability and the disaster preparedness and response strategies available to each. Changes to the physical system are a key factor in adaptation and decisions, but these factors operate in a complex landscape. Through a disaster management lens, the increased frequency of this type of event found in this study may place strains on humanitarian responders and institutions now and in the future. Knowing the change in return periods of the most extreme events can help to provide insight into how humanitarian institutions can evolve to be prepared for the future, in addition to adapting to a broader trend of increasing hydrometeorological disasters globally (CRED, 2015). A worthwhile topic to explore in further assessment of this and related events is the extent to which public and media perception both before (local preparedness, willingness to evacuate) and after (nationwide media coverage and awareness of impacts) may have been impacted by the fact that the storm was not named. However, there is an insufficiency of peerreviewed literature on this topic, even as media outlets in the UK and US have started naming winter storms following the German example (Cutlip, 2013; van Oldenborgh et al., 2015).

It is essential to note that this analysis has pursued an assessment of the climate change context of extreme precipitation events (a climate attribution study) in which we evaluate the impact of climate conditions and changes in radiative forcing on the probability of extreme rainfall events in south Louisiana and the central US Gulf Coast. This analysis is fundamentally different in nature from (and complementary to) assessments of the synoptic chain of events that led to the particular Louisiana extreme precipitation event in August 2016 (we would label that "synoptic attribution"). Synoptic attribution of the event generally involves a clear chain of events that led to the extreme rainfall event in a relatively deterministic fashion. Meanwhile, the climate attribution presented here is fundamentally probabilistic. Although we rec- 
ognize that the synoptic context of this particular extreme event is unique (in fact, all events are unique in detail), we have sought to understand the climate context of the probabilities of a class of events that causes extreme precipitation in the central US Gulf Coast of which this event (floodinducing extreme precipitation in south Louisiana) is a member (Otto et al., 2016). Furthermore, it is possible to assess the climatic context in more detail by assessing more proximate climate drivers than global mean temperature or radiative forcing (e.g., by looking at the impact of particular patterns of SST) or by a more refined assessment of the detailed impact of the superposition of modes of climate variability and multidecadal climate change (e.g., Delworth et al., 2015; Jia et al., 2016). For any particular event, a spectrum of attribution studies (from purely synoptic to purely climatic) could, and perhaps should, be pursued in order to unravel the various factors relevant to that event. Moreover, some of these studies are feasible at rapid attribution timescales while others require more time and focused resources to produce the specific and targeted modeling experiments and observational analyses.

Climate attribution studies such as this one can only be performed with pre-existing multicentennial global simulations with high spatial resolution models. This allowed us to efficiently assess the impact of radiative forcing changes on regional extreme precipitation events. These simulations, obviously, necessitated the long-term research aimed at developing these high-resolution models (e.g., Putman and Lin, 2007; Delworth et al., 2012; Vecchi et al., 2014; Murakami et al., 2015). Furthermore, this work was enabled by a body of work using these models that provided the necessary understanding of the characteristics and fidelity of these models to simulate large-scale and regional climate and weather events over a broad range of scales and phenomena (e.g., Vecchi et al., 2014; Msadek et al., 2014; Delworth et al., 2015; Jia et al., 2015, 2016; Murakami et al., 2015, 2016; Krishnamurthy et al., 2015; Zhang et al., 2015, 2016; Pascale et al., 2016; Van der Wiel et al., 2016).

In particular, this paper follows on a recent analysis of the climatology and $\mathrm{CO}_{2}$ sensitivity of extreme precipitation events over the US in these same models, showing that FLOR and HiFLOR in particular are uniquely capable of capturing central US Gulf Coast precipitation extremes, which have large biases in coarser-resolution models (Van der Wiel et al., 2016). Though the analysis of extreme precipitation events in Van der Wiel et al. (2016) is of a different nature (focusing on much lower return period events, using different statistical methods and focusing at the grid-point scale rather than regional events), the results presented there are consistent with the current analysis. The previous paper showed that in response to increasing $\mathrm{CO}_{2}$ levels in the atmosphere, precipitation extremes along the central US Gulf Coast increase in intensity, with less likely events exhibiting larger fractional intensity increases.
We have here sought to provide a scientifically rigorous rapid assessment of the climate context of this precipitation event, which had tragic consequences, to provide meaningful grounding to the public discussions of this event, given both the intense interest in this specific event and our ongoing work on the general subject of climate and extremes (and precipitation extremes in the US in particular; Van der Wiel et al., 2016). We hope that this study, including our explicit discussion of the assumptions needed to pursue this accelerated assessment, will help push the scientific conversation forward to improve our understanding of the risks and return periods of extreme precipitation in the central US Gulf Coast. The field of rapid attribution analysis is still nascent and may one day lead to such assessments being the normal course of action in response to an extreme event, in order to help provide scientific basis for real-time discussions and in longer-term disaster response and rebuilding. Until that time, studies such as this will likely only be done for select regions and event types where there are sufficient easily accessible data, and a team of scientists with the necessary expertise and ability to make time in their schedules to provide a rapid assessment. We expect that these early efforts at event attribution will expand our knowledge and capabilities on this subject and facilitate further inquiry.

\section{Data availability}

NOAA GFDL climate model data are not readily available globally at all grid points and for all simulations owing to the size of daily global climate model output for high-resolution models with thousands of years of simulations (on the order of hundreds of terabytes). We have made the precipitation data for the central US Gulf Coast, global temperature and ENSO data that were used in this study available at the Climate Explorer: http://climexp.knmi.nl/selectfield_att.cgi.

Competing interests. The authors declare that they have no conflict of interest.

Acknowledgements. We thank Geert Lenderink, Sarah Kew, Nathaniel Johnson, Kieran Bhatia and Fanrong Zeng for their helpful comments on an earlier version of the paper. Funding for this work was supplied by the National Oceanic and Atmospheric Administration, US Department of Commerce to the Geophysical Fluid Dynamics Laboratory, to the Cooperative Institute for Climate Science (award NA14OAR4320106). The statements, findings, conclusions and recommendations are those of the authors and do not necessarily reflect the views of the National Oceanic and Atmospheric Administration, or the US Department of Commerce, or other affiliated institutions. This project was made possible through generous support from donors to Climate Central's World Weather Attribution initiative and the EU project EUCLEIA under grant agreement 607085 . CPC US unified precipitation are data 
provided by the NOAA/OAR/ESRL PSD (Boulder, Colorado, US) and can be downloaded from http://www.esrl.noaa.gov/psd/. USGS data were obtained from the automated website and are provisional and subject to revision. The data are released on the condition that neither the USGS nor the United States Government may be held liable for any damages resulting from their use.

Edited by: H. Cloke

Reviewed by: two anonymous referees

\section{References}

Allen, R. and Burgess, R.: LSU AgCenter predicts floods cost state at least $\$ 110$ million in crop loss, The Advocate, http://www.theadvocate.com/louisiana_flood_2016/article_ a7689806-6946-11e6-a681-ab59c458f55c.html?sr_source=lift_ amplify, last access: 26 August 2016.

American Red Cross: Louisiana Flooding: Red Cross Shelters 10,000+ After Worst Disaster Since Superstorm Sandy, American Red Cross, http://www.redcross.org/news/pressrelease/Louisiana-Flooding-Red-Cross, last access: 23 August 2016 .

American Red Cross: Needs of People in Louisiana Remain Great; Red Cross Still Sheltering 7,000+, Serving Thousands of Meals, American Red Cross, http://www.redcross.org/news/pressrelease/Needs-of-People-in-Louisiana, last access: 23 August 2016b.

Broach, D.: How many houses, people flooded in Louisiana?, NOLA, http://www.nola.com/weather/index.ssf/2016/08/how_ many_people_houses_were_fl.html, last access: 24 August 2016.

Bromwich, J. E.: Flooding in the South Looks a Lot Like Climate Change, The New York Times, http://www.nytimes.com/2016/ 08/17/us/climate-change-louisiana.html, last access: 24 August 2016.

Burton, J. and Demas, A.: Six streamgages Set peaks of record and 50 stations were overtopped by floodwaters, USGS, https://www. usgs.gov/news/usgs-records-historic-flooding-south-louisiana, last access: 22 August 2016.

Centre for Research on the Epidemiology of Disasters (CRED): The Human Cost of Natural Disasters 2015, A Global Perspective; ReliefWeb, http://reliefweb.int/sites/reliefweb.int/files/ resources/PAND_report.pdf, last access: 29 August 2016, 2015.

Chen, C.-T. and Knutson, T.: On the verification and comparison of extreme rainfall indices from climate models, J. Climate, 21, 1605-1621, 2008.

Christidis, N., Stott, P. A., Scaife, A. A., Arribas, A., Jones, G. S., Copsey, D., Knight, J. R., and Tennant, W. J.: A new HadGEM3A-based system for attribution of weather-and climate-related extreme events, J. Climate, 26, 2756-2783, 2013.

Collins, M., Knutti, R., Arblaster, J., Dufresne, J.-L., Fichefet, T., Friedlingstein, P., Gao, X., Gutowski, W. J., Johns, T., Krinner, G., Shongwe, M., Tebaldi, C., Weaver, A. J., and Wehner, M.: Long-term Climate Change: Projections, Commitments and Irreversibility, in: Climate Change 2013: The Physical Science Basis, Contribution of Working Group I to the Fifth Assessment Report of the Intergovernmental Panel on Climate Change, edited by: Stocker, T. F., Qin, D., Plattner, G.-K., Tignor, M., Allen, S.
K., Boschung, J., Nauels, A., Xia, Y., Bex, V., and Midgley, P. M., Cambridge University Press, Cambridge, United Kingdom and New York, NY, USA, 2013.

Coles, S.: An Introduction to Statistical Modeling of Extreme Values, Springer Series in Statistics, London, UK, 2001.

Cutlip, K.: Weather Front, Weatherwise, 66, 2, p. 6, MAS Ultra - School Edition, EBSCOhost, doi:10.1080/00431672.2013.762834, 2013.

Dai, A.: Precipitation characteristics in eighteen coupled climate models, J. Climate, 19, 4605-4630, 2006.

Davies, R.: Louisiana Rivers at Record Levels, President Declares Major Disaster, Floodlist, http://floodlist.com/america/usa/usalouisiana-rivers, last access: 23 August 2016.

Delworth, T. L., Broccoli, A. J., Rosati, A., Stouffer, R. J., Balaji, V., Beesley, J. A., Cooke, W. F., Dixon, K. W., Dunne, J., Dunne, K. A., Durachta, J. W., Findell, K., Ginoux, P., Gnanadesikan, A., Gordon, C. T., Griffies, S., Gudgel, R., Harrison, M., Held, I., Hemler, R., Horowitz., L., Klein, S., Knutson, T., Kushner, P., Langenhorst, A., Lee, H.-C., Lin, S.-J., Lu, J., Malyshev, S., Milly, P. C. D., Ramaswamy, V., Russell, J., Schwarzkopf, M. D., Shevliakova, E., Sirutis, J., Spelman, M., Stern, W., Winton, M., Wittenberg, A., Wyman, B., Zeng, F., and Zhang, R.: GFDL's CM2 global coupled climate models. Part I: Formulation and simulation characteristics, J. Climate, 19, 643-674, 2006.

Delworth, T. L., Rosati, A., Anderson, W., Adcroft, A. J., Balaji, V., Benson, R., Dixon, K., Griffies, S. M., Lee, H. C., Pacanowski, R. C., Vecchi, G. A., Wittenberg, A. T., Zeng, F., and Zhang, R.: Simulated climate and climate change in the GFDL CM2. 5 high-resolution coupled climate model, J. Climate, 25, 27552781, 2012.

Delworth, T. L., Zeng, F., Rosati, A., Vecchi, G. A., and Wittenberg, A. T.: A link between the hiatus in global warming and North American drought, J. Climate, 28, 3834-3845, 2015.

De Michele, C. and Salvadori, G.: On the derived flood frequency distribution: analytical formulation and the influence of antecedent soil moisture condition, J. Hydrol., 262, 245-258, 2002.

Efron, B. and Tibshirani, R. J.: An introduction to the bootstrap, Chapman and Hall, New York, 439 pp., 1998.

Eggert, B., Berg, P., Haerter, J. O., Jacob, D., and Moseley, C.: Temporal and spatial scaling impacts on extreme precipitation, Atmos. Chem. Phys., 15, 5957-5971, doi:10.5194/acp-15-59572015, 2015.

Emanuel, K. and Sobel, A.: Response of tropical sea surface temperature, precipitation, and tropical cyclone-related variables to changes in global and local forcing, Journal of Advances in Modeling Earth Systems, 5, 447-458, doi:10.1002/jame.20032, 2013.

Emanuel, K., Solomon, S., Folini, D., Davis, S., and Cagnazo, C.: Influence of Tropical Tropopause Layer Cooling on Atlantic Hurricane Activity, J. Climate, 26, 2288-2301, doi:10.1175/JCLI-D12-00242.1, 2013.

FEMA: Federal Support for Louisiana Continues, \$127 Million in Financial Assistance Provided to Louisiana Flood Survivors So Far, FEMA, https://www.fema.gov/newsrelease/2016/08/23/federal-support-louisiana-continues, last access: 23 August 2016.

Flato, G., Marotzke, J., Abiodun, B., Braconnot, P., Chou, S. C., Collins, W. J., Cox, P., Driouech, F., Emori, S., Eyring, V., Forest, C., Gleckler, P., Guilyardi, E., Jakob, C., Kattsov, V., Reason, C., and Rummukaines, M.: Evaluation of Climate Models, in: Cli- 
mate Change 2013: The Physical Science Basis, Contribution of Working Group I to the Fifth Assessment Report of the Intergovernmental Panel on Climate Change, Climate Change 2013, 5, 741-866, 2013.

Forster, P. M., Andrews, T., Good, P., Gregory, J. M., Jackson, L. S., and Zelinka, M.: Evaluating adjusted forcing and model spread for historical and future scenarios in the CMIP5 generation of climate models, J. Geophys. Res.-Atmos., 118, 11391150, doi:10.1002/jgrd.50174, 2013.

Gandin, L. S. and Hardin, R.: Objective analysis of meteorological fields, Vol. 242, Israel program for scientific translations Jerusalem, 1965.

GISTEMP Team: GISS Surface Temperature Analysis (GISTEMP), NASA Goddard Institute for Space Studies, http://data.giss.nasa. gov/gistemp/, last access: 8 August 2016.

Haarsma, R. J., Roberts, M. J., Vidale, P. L., Senior, C. A., Bellucci, A., Bao, Q., Chang, P., Corti, S., Fuckar, N. S., Guemas, V., von Hardenberg, J., Hazeleger, W., Kodama, C., Koenigk, T., Leung, L. R., Lu, J., Luo, J.-J., Mao, J., Mizielinski, M. S., Mizuta, R., Nobre, P., Satoh, M., Scoccimarro, E., Semmler, T., Small, J., and von Storch, J.-S.: High Resolution Model Intercomparison Project (HighResMIP v1.0) for CMIP6, Geosci. Model Dev., 9, 4185-4208, doi:10.5194/gmd-9-4185-2016, 2016.

Hansen, J., Ruedy, R., Sato, M., and Lo, K.: Global surface temperature change, Rev. Geophys., 48, RG4004, doi:10.1029/2010RG000345, 2010.

Harris, L. M, Lin, S.-J., and Tu, C. Y.: High resolution climate simulations using GFDL HiRAM with a stretched global grid, J. Climate, 29, 4293-4314, 2016.

Hawkins, E. and Sutton, R.: The potential to narrow uncertainty in regional climate predictions, B. Am. Meteorol. Soc., 90, 10951107, doi:10.1175/2009BAMS2607.1, 2009.

Hazeleger, W., Wang, X., Severijns, C., Stefanescu, S., Bintanja, R., Sterl, A., Wyser, K., Semmler, T., Yang, S., Van den Hurk, B., Van Noije, T., Van der Linden, E., and Van der Wiel, K.: ECEarth V2.2: description and validation of a new seamless earth system prediction model, Clim. Dynam., 39, 2611-2629, 2012.

Hazeleger, W., Wouters, B., Oldenborgh, G. J., Corti, S., Palmer, T., Smith, D., Dunstone, N., Kröger, J., Pohlmann, H., and Storch, J. S.: Predicting multiyear north atlantic ocean variability, J. Geophys. Res.-Oceans, 118, 1087-1098, 2013.

Herscher, R.: Flooding in Louisiana Raises Questions About Timing, Urgency of Warnings, NPR, http://www.npr.org/sections/thetwo-way, last access: 29 August 2016.

Higgins, R. W., Shi, W., Yarosh, E., and Joyce, R.: Improved United States precipitation quality control system and analysis, NOAA, National Weather Service, National Centers for Environmental Prediction, Climate Prediction Center Atlas, 2000.

Huang, B., Banzon, V. F., Freeman, E., Lawrimore, J., Liu, W., Peterson, T. C., Smith, T. M., Thorne, P. W., Woodruff, S. D., and Zhang, H. M.: Extended reconstructed sea surface temperature version 4 (ERSST. v4). Part I: upgrades and intercomparisons, J. Climate, 28, 911-930, 2015.

Jia, L., Yang, X., Vecchi, G. A., Gudgel, R. G., Delworth, T. L., Rosati, A., Stern, W. F., Wittenberg, A. T., Krishnamurthy, L., Zhang, S., and Msadek, R.: Improved seasonal prediction of temperature and precipitation over land in a high-resolution GFDL climate model, J. Climate, 28, 2044-2062, 2015.
Jia, L., Vecchi, G. A., Yang, X., Gudgel, R., Delworth, T., Stern, W., Paffendorf, K., Underwood, S., and Zeng, F.: The Roles of Radiative Forcing, Sea Surface Temperatures, and Atmospheric and Land Initial Conditions in U.S. Summer Warming Episodes, J. Climate, 29, 4121-4135, doi:10.1175/JCLI-D-15-0471.1, 2016.

Kalnay, E., Kanamitsu, M., Kistler, R., Collins, W., Deaven, D., Gandin, L., Iredell, M., Saha, S., White, G., Woollen, J., and Zhu, Y.: The NCEP/NCAR 40-year reanalysis project, B. Am. Meteorol. Soc., 77, 437-471, 1996.

Katsman, C. A., Hazeleger, W., Drijfhout, S. S., van Oldenborgh, G. J., and Burgers, G.: Climate scenarios of sea level rise for the northeast Atlantic Ocean: a study including the effects of ocean dynamics and gravity changes induced by ice melt, Climatic Change, 91, 351-374, 2008.

Keim, B. D. and Faiers, G. E.: Heavy rainfall distributions by season in Louisiana: Synoptic interpretations and quantile estimates, Water Resour. Bull., 32, 117-124, 1996.

Kirtman, B., Power, S. B., Adedoyin, J. A., Boer, G. J., Bojariu, R., Camilloni, I., Doblas-Reyes, F. J., Fiore, A. M., Kimoto, M., Meehl, G. A., Prather, M., Sarr, A., Schär, C., Sutton, R., Van Oldenborgh, G. J., Vecchi, G., and Wang, H.-J.: Near-term climate change: projections and predictability, in: Climate Change 2013: The Physical Science Basis, Contribution of Working Group I to the Fifth Assessment Report of the Intergovernmental Panel on Climate Change, edited by: Stocker, T. F., Qin, D., Plattner, G.-K., Tignor, M., Allen, S. K., Boschung, J., Nauels, A., Xia, Y., Bex, V., and Midgley, P. M., Cambridge University Press, Cambridge, United Kingdom and New York, NY, USA, 2013.

Knapp, K. R., Kruk, M. C., Levinson, D. H., Diamond, H. J., and Neumann, C. J.: The international best track archive for climate stewardship (IBTrACS), B. Am. Meteorol. Soc., 91, 363-376, doi:10.1175/2009BAMS2755.1, 2010.

Knutson, T. R., Sirutis, J. J., Vecchi, G. A., Garner, S., Zhao, M., Kim, H. S., Bender, M., Tuleya, R. E., Held, I. M., and Villarini, G.: Dynamical downscaling projections of twenty-first-century Atlantic hurricane activity: CMIP3 and CMIP5 model-based scenarios, J. Climate, 26, 6591-6617, 2013.

Krishnamurthy, L., Vecchi, G., Msadek, R., Wittenberg, A., Delworth, T., and Zeng, F.: The Seasonality of the Great Plains LowLevel Jet and ENSO Relationship, J. Climate, 28, 4525-4544, doi:10.1175/JCLI-D-14-00590.1, 2015.

Lehmann, J., Coumou, D., and Frieler, K.: Increased record breaking precipitation events under global warming, Climatic Change, 132, 501-505, doi:10.1007/s10584-015-1434-y, 2015.

Lenderink, G. and Attema, J.: A simple scaling approach to produce climate scenarios of local precipitation extremes for the Netherlands, Environ. Res. Lett., 10, 085001, doi:10.1088/17489326/10/8/085001, 2015.

Lin, N., Emanuel, K., Oppenheimer, M., and Vanmarcke, E.: Physically based assessment of hurricane surge threat under climate change, Nature Climate Change, 2, 462-467, 2012.

Lin, N., Lane, P., Emanuel, K. A., Sullivan, R. M., and Donnelly, J. P.: Heightened hurricane surge risk in northwest Florida revealed from climatological-hydrodynamic modeling and paleorecord reconstruction, J. Geophys. Res.-Atmos., 119, 86068623, doi:10.1002/2014JD021584, 2014.

Little, C. M., Horton, R. M., Kopp, R. E., Oppenheimer, M., Vecchi, G. A., and Villarini, G.: Joint projections of US East Coast sea 
level and storm surge, Nature Climate Change, 5, 1114-1120, doi:10.1038/nclimate2801, 2015.

Massey, N., Jones, R., Otto, F. E. L., Aina, T., Wilson, S., Murphy, J. M., Hassell, D., Yamazaki, Y. H., and Alle, M. R.: weather@home - development and validation of a very large ensemble modelling system for probabilistic event attribution, Q. J. Roy. Meteor. Soc., 141, 1528-1545, doi:10.1002/qj.2455, 2015.

Menne, M. J., Durre, I., Vose, R. S., Gleason, B. E., and Houston, T. G.: An overview of the Global Historical Climatology NetworkDaily Database, J. Atmos. Ocean. Tech., 29, 897-910, 2012.

Menne, M. J., Durre, I., Korzeniewski, B., McNeal, S., Thomas, K., Yin, X., Anthony, S., Ray, R., Vose, R. S., Gleason, B. E., and Houston, T. G.: Global Historical Climatology Network-Daily (GHCN-Daily), Version 3.22, NOAA National Climatic Data Center, http://doi.org/10.7289/V5D21VHZ, last access: $19 \mathrm{Au}-$ gust 2016.

Milman, O.: Disasters like Louisiana floods will worsen as planet warms, scientists warn, The Guardian, https://www.theguardian.com/environment/2016/aug/16/ louisiana-flooding-natural-disaster-weather-climate-change, last access: 24 August 2016.

Moftakhari, H. R., AghaKouchak, A., Sanders, B. F., Feldman, D. L., Sweet, W., Matthew, R. A., and Luke, A.: Increased nuisance flooding along the coasts of the United States due to sea level rise: Past and future, Geophys. Res. Lett., 42, 9846-9852, doi:10.1002/2015GL066072, 2015.

Msadek, R., Vecchi, G. A., Winton, M., and Gudgel, R.: Importance of initial conditions in seasonal predictions of Arctic sea ice extent, Geophys. Res. Lett., 41, 5208-5215, doi:10.1002/2014GL060799, 2014.

Murakami, H. and Wang, B.: Future Change of North Atlantic Tropical Cyclone Tracks: Projection by a 20-kmMesh Global Atmospheric Model, J. Climate, 23, 2688-2721, doi:10.1175/2010JCLI3338.1, 2010.

Murakami, H., Vecchi, G. A, Underwood, S., Delworth, T., Wittenberg, A. T., Anderson, W., Chen, J.-H., Gudgel, R., Harris, L., Lin, S.-J., and Zeng, F.: Simulation and prediction of Category 4 and 5 hurricanes in the high-resolution GFDL HiFLOR coupled climate model, J. Climate, 28, 9058-9079, doi:10.1175/JCLI-D15-0216.1, 2015.

Murakami, H., Vecchi, G. A., Villarini, G., Delworth, T., Gudgel, R., Underwood, S. D., Yang, X., Zhang, W., and Lin, S.-J.: Seasonal Forecasts of Major Hurricanes and Landfalling Tropical Cyclones using a High-Resolution GFDL Coupled Climate Model, J. Climate, 29, 7977-7989, doi:10.1175/JCLI-D16-0233.1, 2016.

National Weather Service: Southern and Eastern U.S. Heavy Rainfall, storm summaries 1-19, http://www.wpc.ncep.noaa. gov/winter_storm_summaries/storm15/storm15_archive.shtml, last access: 23 August 2016.

New Orleans area forecast discussions (PIL=AFDLIX): https:// mesonet.agron.iastate.edu/wx/afos/, last access: 24 August 2016.

O'Gorman, P. A.: Precipitation extremes under climate change, Current Climate Change Reports, 1, 49-59, 2015.

Otto, F. E., Van Oldenborgh, G. J., Eden, J., Stott, P. A., Karoly, D. J., and Allen, M. R.: The attribution question, Nature Climate Change, 6, 813-816, 2016.

Pascale, S., Bordoni, S., Kapnick, S. B., Vecchi, G. A., Jia, L., Delworth, T. L., Underwood, S., and Anderson, W.: The impact of horizontal resolution on North American monsoon Gulf of California moisture surges in a suite of coupled global climate models, J. Climate, 29, 7911-7936, doi:10.1175/JCLI-D-16-0199.1, 2016.

Pinter, N., van der Ploeg, R. R., Schweigert, P., and Hoefer, G.: Flood magnification on the River Rhine, Hydrol. Process., 20, 147-164, 2006.

Putman, W. M. and Lin, S.-J.: Finite-volume transport on various cubed-sphere grids, J. Comput. Phys., 227, 55-78, 2007.

Rantz, S. E. et al.: Measurement and computation of streamflow: volume 2, computation of discharge (No. 2175), USGPO, https: //pubs.usgs.gov/wsp/wsp2175/pdf/WSP2175_vol2a.pdf (last access: 24 August 2016), 1982.

Rayner, N. A., Parker, D. E., Horton, E. B., Folland, C. K., Alexander, L. V., Rowell, D. P., Kent, E. C., and Kaplan, A.: Global analyses of sea surface temperature, sea ice, and night marine air temperature since the late nineteenth century, J. Geophys. Res.Atmos., 108, 4407, doi:10.1029/2002JD002670, 2003.

Stafford, R. T.: Stafford disaster relief and emergency assistance act, Public Law, 10, 106-390, 2000.

Scherrer, S. C., Fischer, E. M., Posselt, R., Liniger, M. A., CrociMaspoli, M., and Knutti, R.: Emerging trends in heavy precipitation and hot temperature extremes in Switzerland, J. Geophys. Res.-Atmos., 121, 2626-2637, doi:10.1002/2015JD024634, 2016.

Schleifstein, M.: Louisiana Flood of 2016 resulted from "1,000year" rain in 2 days, NOLA, http://www.nola.com/weather/ index.ssf/2016/08/louisiana_flood_of_2016_result.html, last access: 23 August 2016.

Sterl, A., van den Brink, H., de Vries, H., Haarsma, R., and van Meijgaard, E.: An ensemble study of extreme storm surge related water levels in the North Sea in a changing climate, Ocean Sci., 5, 369-378, doi:10.5194/os-5-369-2009, 2009.

Strum, B.: Damage Grows from Louisiana Flood, Wall Street Journal, http://www.wsj.com/articles/, last access: 23 August 2016.

Taylor, K. E., Stouffer, R. J., and Meehl, G. A.: An overview of CMIP5 and the experiment design, B. Am. Meteorol. Soc., 93, 485-498, 2012.

Tramblay, Y., Bouvier, C., Martin, C., Didon-Lescot, J. F., Todorovik, D., and Domergue, J. M.: Assessment of initial soil moisture conditions for event-based rainfall-runoff modelling, J. Hydrol., 387, 176-187, 2010.

Van der Wiel, K., Kapnick, S. B., Vecchi, G. A., Cooke, W. F., Delworth, T. L., Jia, L., Murakami, H., Underwood, S., and Zeng, F.: The resolution dependence of contiguous U.S. precipitation extremes in response to $\mathrm{CO}_{2}$ forcing, J. Climate, 29, 7991-8012, doi:10.1175/JCLI-D-16-0307.1, 2016.

van Oldenborgh, G. J., Otto, F. E. L., Haustein, K., and Cullen, H.: Climate change increases the probability of heavy rains like those of storm Desmond in the UK - an event attribution study in nearreal time, Hydrol. Earth Syst. Sci. Discuss., 12, 13197-13216, doi:10.5194/hessd-12-13197-2015, 2015.

van Oldenborgh, G. J., Philip, S., Aalbers, E., Vautard, R., Otto, F., Haustein, K., Habets, F., Singh, R., and Cullen, H.: Rapid attribution of the May/June 2016 flood-inducing precipitation in France and Germany to climate change, Hydrol. Earth Syst. Sci. Discuss., doi:10.5194/hess-2016-308, in review, 2016.

Van Vuuren, D. P., Edmonds, J., Kainuma, M., Riahi, K., Thomson, A., Hibbard, K., Hurtt, G. C., Kram, T., Krey, V., Lamar- 
que, J. F., Masui, T., Meinshausen, M., Nakicenovic, N., Smith, S., and Rose, S.: The representative concentration pathways: an overview, Climatic Change, 109, 5-31, 2011.

Vecchi, G. A. and Soden, B. J.: Effect of remote sea surface temperature change on tropical cyclone potential intensity, Nature, 450, 1066-1070, doi:10.1038/nature06423, 2007.

Vecchi, G. A., Fueglistaler, S., Held, I. M., Knutson, T. R., and Zhao, M.: Impacts of Atmospheric Temperature Changes on Tropical Cyclone Activity, J. Climate, 26, 3877-3891, doi:10.1175/JCLI-D-12-00503.1, 2013.

Vecchi, G. A., Delworth, T., Gudgel, R., Kapnick, S. B., Rosati, A., Wittenberg, A. T., Zeng, F., Anderson, W., Balaji, V., Dixon, K. Jia, L., Kim, H.-S., Krishnamurthy, L., Msadek, R., Stern, W. F., Underwood, S. D., Villarini, G., Yang, X., and Zhang, S.: On the seasonal forecasting of regional tropical cyclone activity, J. Climate, 27, 7994-8016, 2014.

Villarini, G., Goska, R., Smith, J. A., and Vecchi, G. A.: North Atlantic tropical cyclones and US flooding, B. Am. Meteorol. Soc., 95, 1381-1388, 2014.

Walsh, K., Camargo, S., Vecchi, G., Daloz, A., Elsner, J., Emanuel, K., Horn, M., Lim, Y.-K., Roberts, M., Patricola, C., Scoccimarro, E., Sobel, A., Strazzo, S., Villarini, G., Wehner, M., Zhao, M., Kossin, J., LaRow, T., Oouchi, K., Schubert, S., Wang, H., Bacmeister, J., Chang, P., Chauvin, F., Jablonowski, C., Kumar, A., Murakami, H., Ose, T., Reed, K., Saravanan, R., Yamada, Y., Zarzycki, C., Vidale, P., Jonas, J., and Henderson, N.: Hurricanes and climate: the U.S. CLIVAR working group on hurricanes, B. Am. Meteorol. Soc., 96, 997-1017, doi:10.1175/BAMS-D-1300242.1, 2015.
Yang, X., Vecchi, G. A., Gudgel, R. G., Delworth, T. L., Zhang, S., Rosati, A., Jia, L., Stern, W. F., Wittenberg, A. T., Kapnick, S., and Msadek, R.: Seasonal predictability of extratropical storm tracks in GFDL's high-resolution climate prediction model, J. Climate, 28, 3592-3611, 2015.

Zhang, W., Leung, Y., and Fraedrich, K.: Different El Niño types and intense typhoons in the Western North Pacific, Clim. Dynam., 44, 2965-2977, 2015.

Zhang, W., Vecchi, G. A., Murakami, H., Delworth, T., Wittenberg, A. T., Anderson, W., Rosati, A., Underwood, S., Harris L., Gudgel, R., Lin, S.-J., Villarini, G., and Chen, J.-H.: Improved Simulation of Tropical Cyclone Responses to ENSO in the Western North Pacific in the High-Resolution GFDL HiFLOR Coupled Climate Model, J. Climate, 29, 1391-1415, doi:10.1175/JCLI-D-15-0475.1, 2016. 